AUTARQUIA ASSOCIADA À UNIVERSIDADE DE SÃO PAULO

\title{
CARACTERIZAÇÃO BIOQUÍMICA DE LESÕES NEOPLÁSICAS VIA ESPECTROSCOPIA DE ABSORÇÃO NO INFRAVERMELHO POR TRANSFORMADA DE FOURIER
}

\author{
Cássio Aparecido Lima
}

\begin{abstract}
Dissertação apresentada como parte dos requisitos para obtenção do Grau de Mestre em Ciências na Área de Tecnologia Nuclear - Materiais
\end{abstract}

Orientadora:

Profa. Dra. Denise Maria Zezell 


\title{
INSTITUTO DE PESQUISAS ENERGÉTICAS E NUCLEARES
}

Autarquia associada à Universidade de São Paulo

\section{CARACTERIZAÇÃO BIOQUÍMICA DE LESÕES NEOPLÁSICAS VIA ESPECTROSCOPIA DE ABSORÇÃO NO INFRAVERMELHO POR TRANSFORMADA DE FOURIER}

\author{
Cássio Aparecido Lima
}

\author{
Dissertação apresentada como parte dos \\ requisitos para obtenção do Grau de \\ Mestre em Ciências na Área \\ de Tecnologia Nuclear - Materiais \\ Orientadora: \\ Profa. Dra. Denise Maria Zezell
}

Versão Corrigida

Versão Original disponível no IPEN

São Paulo

2015 
Aos meus pais, Lenino e Idelma

Que apoiaram e acreditaram em meus sonhos, mesmo que estes ocasionassem nossa separação física! 


\section{AGRADECIMENTO ESPECIAL}

À Profa. Dra. Denise Maria Zezell, uma amiga que a hierarquia acadêmica me obriga a chamar de orientadora. Muitíssimo obrigado pelos ensinamentos, apoio, paciência, carinho e por ter aberto as portas de seu laboratório e aceito o desafio de me orientar sem mesmo me conhecer.

Agradeço pela humildade nas inúmeras vezes que se disponibilizou a sentar do meu lado não só pra ensinar, mas também pra aprender junto comigo e não poupar esforços na construção de meu conhecimento, seja ele acadêmico, técnico, político ou pessoal.

(:) 


\section{AGRADECIMENTOS}

Ao Instituto de Pesquisas Energéticas e Nucleares (IPEN) e ao Centro de Lasers e Aplicações (CLA), pela infraestrutura concedida nestes dois anos de pós-graduação.

Aos meus amigos de graduação Matheus, Vanbasten, Flávia, Priscila, Dalson, Adriana e demais membros da minha eterna república amarela.

Aos meus amigos Adrielle Caxa e Uiran Silva, pelo apoio e recepção quando cheguei em São Paulo.

Às minhas amigas Maíra, Carol, Márcia e Anne pelo apoio, companheirismo, amizade e paciência nesses dois anos.

À minha amiga e vizinha Letícia por me acalmar nos momentos de maior estresse e ter se disposto a aprender o meu trabalho para me ajudar com o mesmo.

À minha amiga Claudia Zamataro por exercer sua profissão de dentista fora de seu consultório e ter me permitido sorrir sempre.

Aos colegas do Centro de Lasers e Aplicações, Pedro, Derly, Lucas de Pretto, Christine Kores, Camila, China e Tânia.

Ao meu incrível grupo de Biofotônica.

À todos os funcionários do Centro de Lasers e Aplicações, em especial ao Sr. Luís pelas inúmeras vezes em que se preocupou em fazer café nos dias em que era necessário ficar no prédio após seu expediente.

Ao CNPq pela bolsa de mestrado concedida (133322/2013-0)

À Fapesp - processos CEPID: Centro de Pesquisa Em Óptica e Fotônica (CEPOF) 98/14270-8 e CEPOF 05/51689-2 e ao CNPq INCT Instituto Nacional de Ciência e Tecnologia Fotônica processo 573.916/2008-0.

Muito Obrigado! =) 
A descoberta consiste em ver o que todo mundo viu e pensar o que ninguém pensou.

- Jonathan Swift - 


\title{
Caracterização bioquímica de lesões neoplásicas via espectroscopia de absorção no infravermelho por transformada de Fourier
}

\author{
Cássio Aparecido Lima
}

\begin{abstract}
Resumo
Cânceres de pele não melanoma (CPNM) representam 95\% das neoplasias cutâneas, dentre as quais o carcinoma espinocelular (CEC) é a forma mais agressiva devido a seu padrão de crescimento invasivo e possivelmente metastático. O padrão ouro para o diagnóstico é o exame clínico e avaliação histopatológica, que são subjetivos e dependem da experiência do médico e patologista envolvidos no procedimento. Considerando que o diagnóstico precoce é fundamental para alcançar um tratamento com resultados favoráveis, o presente trabalho utilizou a espectroscopia FTIR (Fourier transform infrared spectroscopy) para avaliar as alterações bioquímicas em pele normal causadas por lesões neoplásicas precursoras de carcinoma espinocelular. Para isto, as lesões foram induzidas quimicamente no dorso de camundongos Swiss via aplicação tópica de 9,10-dimetil-1,2-benzantraceno (DMBA) e 12-tetradecanoforbol-13-acetato (TPA) por um período de 28 semanas. Os espectros de absorção no infravermelho por transformada de Fourier foram coletados na região do infravermelho médio $\left(4000-400 \mathrm{~cm}^{-1}\right)$ no modo de reflexão total atenuada (ATR) e pré-processados para análise posterior. Considerou-se a amplitude da segunda derivada dos espectros de absorção como critério de comparação entre os grupos, nos quais foi observado redução de fibras colágenas e glicogênio no tecido neoplásico, assim como o aumento na intensidade de absorção de modos vibracionais associados a ácidos nucleicos e conteúdo proteico. A técnica de análise por agrupamento (HCA) foi utilizada para classificação dos espectros de tecidos normal e neoplásico, na qual obteve-se 92,6\% de acurácia na discriminação dos dados. Diante disso, conclui-se que a espectroscopia FTIR associada a análise por agrupamento apresenta-se como uma potencial ferramenta para complementar a análise histopatológica na rotina clínica durante o diagnóstico de carcinoma espinocelular.
\end{abstract}




\title{
Biochemical characterization of neoplastic lesions using Fourier transform Infrared spectroscopy
}

\author{
Cássio Aparecido Lima
}

\begin{abstract}
Nonmelanoma skin cancers represent $95 \%$ of cutaneous neoplasms, which squamous cell carcinoma (SCC) is the more aggressive form due to its invasive growth pattern and potentially metastatic. Histopathologycal analysis and clinical exam are the gold standard for diagnosis, which are subjective and depend on the experience of the physician and pathologist involved in the procedure. Considering that early diagnosis has fundamental importance to achieving a treatment with favorable results, this study used FTIR spectroscopy (Fourier transform Infrared spectroscopy) to assess the biochemical changes in normal skin caused by neoplastic lesions precursors of squamous cell carcinoma. For this, the lesions were chemically induced in the back of Swiss mice by topical application of 9,10dimethyl-1,2-benzanthracene (DMBA) and 12 tetradecanoforbol-13-acetate (TPA) for a 28week period. Fourier transform infrared spectra from normal and neoplastic tissue were collected in the mid-infrared region (4000-400 $\mathrm{cm}^{-1}$ ) using attenuated total reflection (ATR) sampling mode and pre-processed for group comparison. The amplitude of second derivative was considered as criteria for group comparison, which showed a reduction of collagen fibers and glycogen content in the neoplastic tissue, as well as increasing in the vibrational modes associated with nucleic acids and protein content. Hierarchical Cluster Analysis (HCA) was used for classification of spectra from neoplastic and normal tissue and obtained an accuracy of $92,6 \%$ sorting the data. In this sense, we conclude that FTIR spectroscopy associated with HCA presents as a potential tool for complementary histopathological analysis in the clinical diagnosis of squamous cell carcinoma.
\end{abstract}




\section{Sumário}

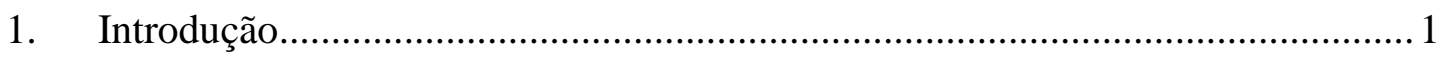

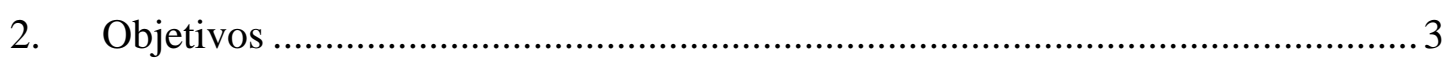

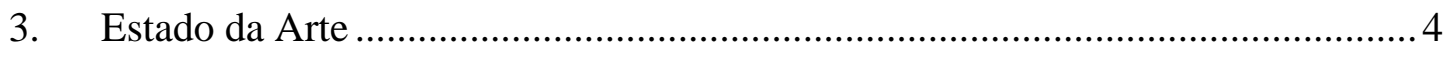

3.1. Carcinoma espinocelular cutâneo ......................................................... 4

3.2. Espectroscopia de absorção no infravermelho por transformada de

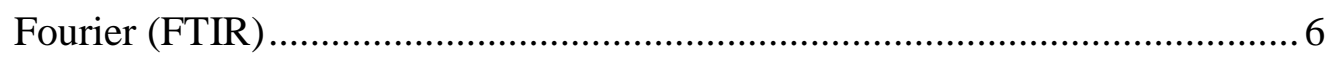

3.3. Espectroscopia FTIR como ferramenta diagnóstica de neoplasias ....... 10

3.3.1. Proteínas ...................................................................................... 11

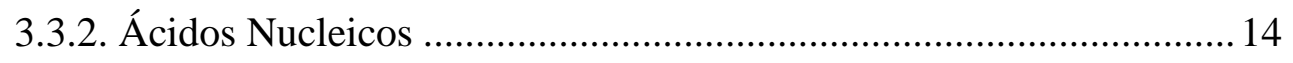

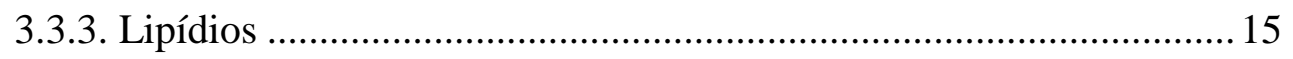

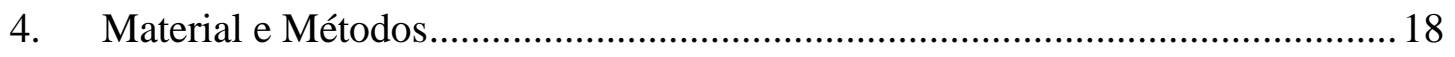

4.1. Preparação de amostras ........................................................... 18

4.2. Aquisição de espectros ........................................................ 19

4.3. Desparafinização das lâminas ................................................... 20

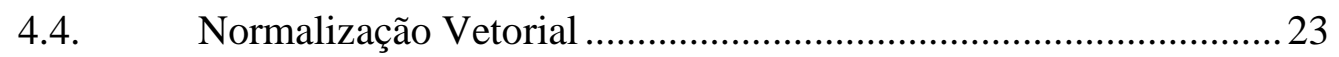

4.5. Derivada de segunda ordem e filtro de Savitzky-Golay ................24

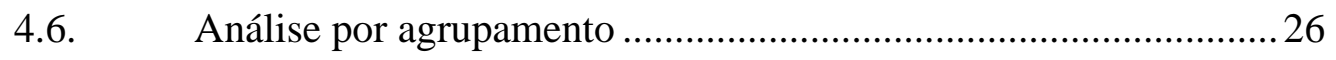

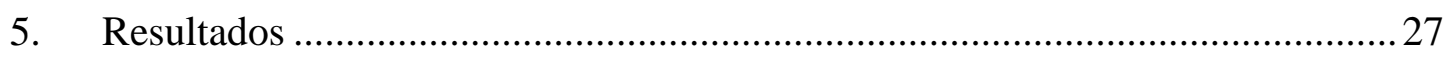

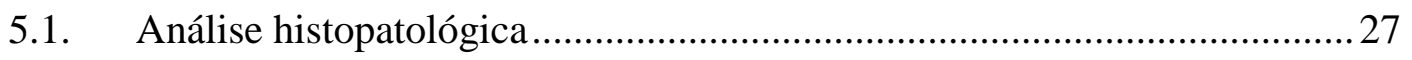

5.2. Caracterização bioquímica via Espectroscopia FTIR ...............................28

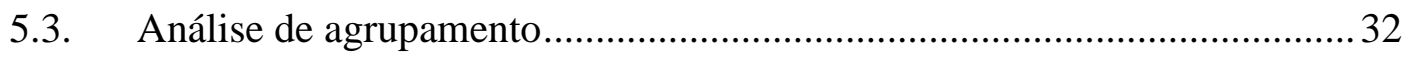




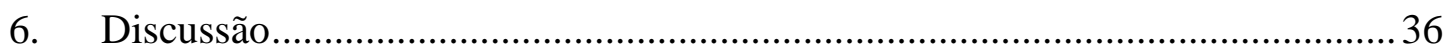

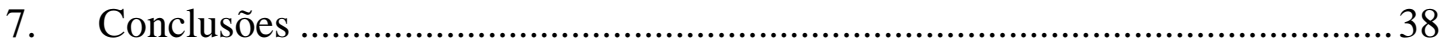

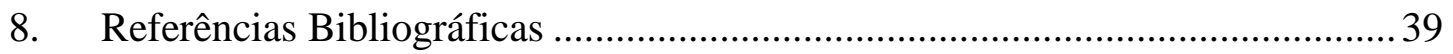




\section{LISTA DE FIGURAS}

Figura 1. Estimativa de câncer no Brasil para o ano de 2014 ....................................5

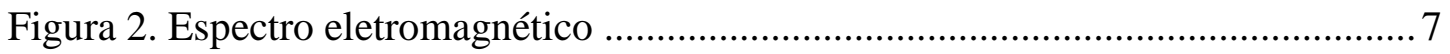

Figura 3. Esquema de funcionamento de um espectrofotômetro FTIR ....................... 8

Figura 4. Principais configurações experimentais utilizadas na obtenção de espectros

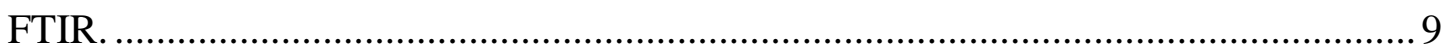

Figura 5. Estrutura geral de um aminoácido. ........................................................ 12

Figura 6: Ligação peptídica entre dois aminoácidos .............................................. 12

Figura 7. Esquema das estruturas de proteínas. ................................................... 13

Figura 8. Principais estruturas secundárias encontradas em proteínas ...................... 13

Figura 9. Estrutura de um nucleotídeo ............................................................. 14

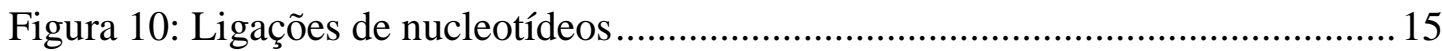

Figura 11. Formação de molécula de glicerídeo triplo (triglicerídeo) a partir de três ácidos graxos e uma molécula de glicerol.............................................................. 16

Figura 12. Molécula de fosfolipídio à esquerda e bicamada fosfolipídica à direita ... 16

Figura 13. Instilação de carcinógenos em camundongo tricotomizado ...................... 18

Figura 14: Espectrofotômetro FTIR acoplado à acessório ATR (à esquerda); Corte histológico sobre o diamante do ATR (à direita) .....................................................2 20

Figura 15: Varredura efetuada em cada corte durante a aquisição de espectros.........20

Figura 16. Espectro de absorção no infravermelho de lâmina com parafina ..............21

Figura 17. Espectros FTIR de tecido cutâneo antes (linha preta) e após (linha vermelha)

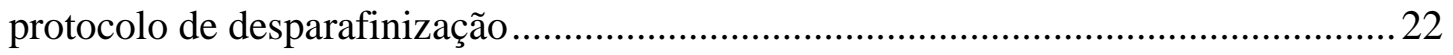


Figura 18: Espectros obtidos de uma mesma região em uma amostra antes e depois da normalização vetorial: não normalizados (à esquerda) e normalizados vetorialmente (à direita) .24

Figura 19. Simulação de banda resultante $(\mathrm{G} 1+\mathrm{G} 2)$ da sobreposição de duas gaussianas G1 e G2 (à esquerda) e segunda derivada das funções simuladas (à direita) 25

Figura 20. Microscopia de luz de cortes histológicos corados com H\&E. (A) pele saudável; (B) lesão neoplásica .27

Figura 21. Espectro médio para tecido normal (linha azul) e tecido neoplásico (linha vermelha). 28

Figura 22. Média das derivadas de segunda ordem da absorbância de espectros provenientes de tecido normal e neoplásico. 29

Figura 23. Valores obtidos para a razão da intensidade de absorção das bandas de tecido neoplásico por tecido normal 31

Figura 24. Classificação dos espectros de tecido normal e neoplásico em função do nível de similaridade para todos os espectros obtidos. 33 Figura 25. Classificação dos espectros de tecido normal e neoplásico em função do nível de similaridade para o espectro médio por corte histológico. 35 


\section{Introdução}

Define-se como tumor ou neoplasma o crescimento e proliferação anormal de células que sofreram mutações nos genes responsáveis pela regulação dos processos básicos de proliferação, diferenciação e apoptose celular [1,2]. Câncer é a designação genérica de qualquer tumor maligno e atualmente caracteriza mais de 100 doenças que têm em comum o crescimento desordenado de células, que podem se espalhar pelo organismo e levar o indivíduo a óbito [3].

Segundo a Organização Mundial da Saúde (OMS), o câncer é a terceira doença que mais mata no mundo e estima-se a morte de 27 milhões de pessoas no ano de 2030 ocasionadas pela doença [4]. No Brasil, o Instituto Nacional do Câncer (INCA) estimou a ocorrência de 728.580 novos casos de câncer para o ano de 2014, dos quais aproximadamente $30 \%$ correspondem aos tumores de pele do tipo não-melanoma (CPNM) [5].

Dentre as diferentes linhagens existentes para CPNM, o carcinoma espinocelular (CEC) é a forma mais agressiva devido a seu padrão de crescimento invasivo e possivelmente metastático. Na prática clínica o diagnóstico de CEC é inicialmente feito por um médico que determina visualmente se uma lesão cutânea apresenta características cancerosas, e caso considere necessário, extrai parte da lesão via biópsia para maior precisão diagnóstica via análise histopatológica [6]. Contudo, tanto o exame clínico quanto a avaliação histopatológica são subjetivos e dependem da experiência do médico e patologista envolvidos no procedimento.

Considerando que o diagnóstico precoce é fundamental para alcançar um tratamento com resultados favoráveis, a busca por técnicas e novos métodos de diagnóstico tem se tornado uma área ativa e promissora. Dentre as técnicas atualmente estudadas, a biópsia óptica, representada por técnicas fotônicas, tem obtido grande sucesso na caracterização de materiais com origem biológica. A espectroscopia vibracional, constituída pelas técnicas de espalhamento Raman e de absorção no infravermelho por transformada de Fourier (FTIR), 
são de especial interesse devido a sua alta sensibilidade na detecção de alterações bioquímicas e moleculares em tecidos biológicos [7-13].

Em particular, a região do infravermelho médio obtida com a espectroscopia FTIR compreende modos vibracionais associados a importantes componentes bioquímicos celulares, os quais podem ser utilizados como marcadores na identificação de alterações metabólicas sofridas pela célula durante o processo de carcinogênese. 


\section{Objetivos}

Analisar as alterações bioquímicas ocasionadas pela carcinogênese química em tecido cutâneo, por espectroscopia FTIR, para avaliar a habilidade da análise hierárquica de agrupamento em classificar amostras de pele normal e neoplásica. 


\section{Estado da Arte}

\subsection{Carcinoma espinocelular cutâneo}

Tumor ou neoplasma (do grego "neo", novo e "plasma", formação) é a designação genérica para o crescimento e proliferação anormal de células. A formação de tumores decorre de mutações nos genes que regulam o ciclo celular, as vias apoptóticas e as vias de reparo aos danos do DNA, possibilitando que as células se reproduzam mais rapidamente que células normais. De acordo com sua cinética de crescimento e morfologia, os tumores podem ser caracterizados como benignos ou malignos. Tumores benignos são constituídos por células que se multiplicam vagarosamente, se assemelham ao tecido original e não apresentam caráter invasivo. Por outro lado, as células de tumores malignos em geral se reproduzem rapidamente e podem se disseminar pelo organismo (metástase) de maneira a afetar o funcionamento de outros órgãos. Câncer é a designação genérica de qualquer tumor maligno [1,2], de forma que atualmente mais de 100 doenças que têm em comum o crescimento desordenado de células potencialmente metastáticas são classificadas como câncer [3].

Segundo a Organização Mundial da Saúde (OMS), o câncer ocupa o terceiro lugar no ranking mundial de mortes causadas por doenças, perdendo apenas para as doenças cardiovasculares e pulmonares. Para o ano de 2030 pode-se esperar 27 milhões de casos incidentes de câncer, 17 milhões de óbitos por câncer e 75 milhões de pessoas vivendo com a doença [4]. No Brasil, o Instituto Nacional do Câncer (INCA) estimou a ocorrência de 728.580 novos casos de câncer para o ano de 2014, dos quais aproximadamente $30 \%$ correspondem aos tumores de pele do tipo não-melanoma (CPNM) como mostrado na Figura $1[5]$. 


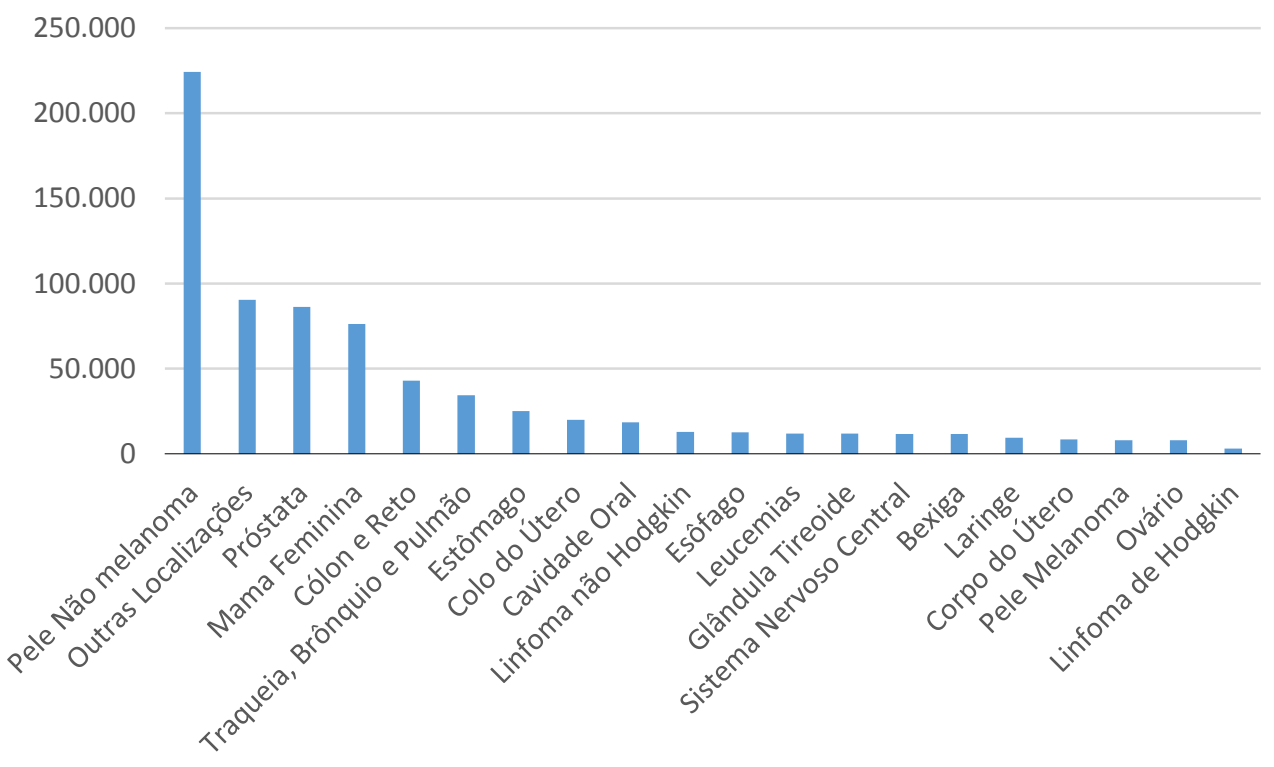

Figura 1. Estimativa da incidência de câncer no Brasil para o ano de 2014 [5]

O elevado número de casos para CPNM no Brasil está relacionado com a luz do Sol que a população é diariamente exposta. Comprimentos de onda na faixa do ultravioleta (290$320 \mathrm{~nm}$ ) que constituem a radiação solar, induzem a produção de espécies reativas de oxigênio (ROS, do inglês reactive oxygen species) que estão envolvidas em processos e vias de sinalização que danificam o DNA celular, podendo levar a célula a se reproduzir anormalmente e, consequentemente, ao desenvolvimento de câncer [14-17].

O CPNM pode apresentar tumores de diferentes linhagens, sendo os mais frequentes o carcinoma basocelular (CBC) e o carcinoma espinocelular (CEC). O CBC tem origem nas células basais da epiderme, é responsável por $70 \%$ dos diagnósticos, possui crescimento lento, é localmente invasivo e raramente apresenta metástases [14,15]. Por outro lado, o CEC apresenta um padrão de crescimento destrutivo e metastático, origina-se em células do estrato espinhoso e corresponde a $25 \%$ dos casos registrados [14-16].

Tumores de pele não-melanoma são neoplasias de bom prognóstico e com altas taxas de cura, se detectados precocemente. Na prática clínica o diagnóstico de CEC é inicialmente feito por um médico que determina visualmente se uma lesão cutânea apresenta características de malignidade, e caso considere necessário, extrai parte da lesão via biópsia para maior precisão diagnóstica via análise histopatológica [6,18]. 
A análise histopatológica é realizada por um patologista que determina se uma lesão é neoplásica a partir das características anatomopatológicas apresentadas pelo tecido. A classificação histopatológica proposta por Broders em 1921 é usualmente a base para a gradação de CEC e divide os tumores em três categorias: grau I (mais de $75 \%$ das células bem diferenciadas), grau II (50 a 75\% de células bem diferenciadas) e grau III (25 a 50\% de células bem diferenciadas) [19]. As lesões macroscópicas relacionadas ao CEC surgem como pápulas escamosas avermelhadas na pele e são formadas por cordões de células epiteliais relativamente grandes e atípicas com núcleo pleomórfico e mitoses frequentes em direção a derme e hipoderme. A célula individual exibe alto grau de quetarinização, forma cilíndrica, núcleo picnótico, citoplasma opaco e intensamente eosinófilo [19,20]. O potencial metastático do CEC para sítios distantes da lesão primária são raros e quando ocorrem, são comuns em nódulos linfáticos [21].

Assim como o exame clínico, o diagnóstico de carcinoma espinocelular via análise histopatológica é subjetivo e depende da experiência do patologista. Além disso, lesões préneoplásicas (queratose actínica, queratoacantoma e doença de Bowen) dificultam o diagnóstico precoce devido a semelhança morfológica de tais lesões com o carcinoma espinocelular em estágio inicial [18].

Considerando que o diagnóstico precoce é fundamental para alcançar um tratamento com resultados favoráveis, a busca por técnicas auxiliares que consigam detectar o câncer ainda em estágio inicial têm sido tema de diversos trabalhos científicos.

\subsection{Espectroscopia de absorção no infravermelho por transformada de Fourier (FTIR)}

Define-se como espectroscopia o conjunto de técnicas de análise que utilizam a interação da radiação eletromagnética com a matéria para obter informações físicas e químicas de determinado material. Na espectroscopia no infravermelho, como o nome sugere, utiliza-se a região do infravermelho do espectro eletromagnético, que corresponde aos comprimentos de onda $(\lambda)$ maiores que $0,7 \mu \mathrm{m}$ até $1 \mathrm{~mm}$ (Figura 2) [22,23]. 


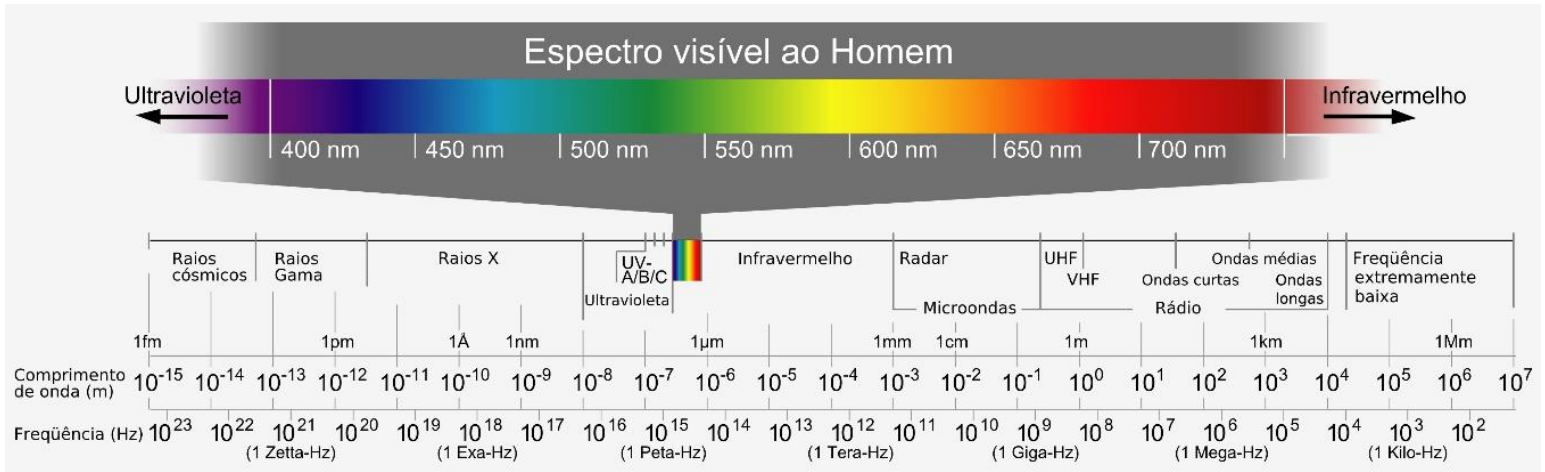

Figura 2. Espectro eletromagnético[24]

A energia associada ao fóton característico de determinada radiação é inversamente proporcional ao comprimento de onda da mesma [22]. Diante disso, ao contrário do obtido na espectroscopia de absorção eletrônica UV-VIS, a radiação na região do infravermelho possui baixa energia e não promove transições eletrônicas no material [23].

As moléculas de um material estão em constante movimento e possuem frequências naturais associadas a seus movimentos de vibração e rotação. Quando uma molécula vibra, o momento de dipolo intrínseco às ligações químicas que constituem a mesma pode sofrer variação. Se o momento de dipolo oscilar com a mesma frequência de determinada radiação incidente, estes interagem e a energia da radiação incidente é absorvida via ressonância, ocasionando o aumento da amplitude da vibração molecular [23,25]. A vibração dos átomos no interior de uma molécula apresenta energia compatível com a região do espectro eletromagnético correspondente ao infravermelho, sendo por isso utilizada no estudo dos modos vibracionais de um material na espectroscopia de absorção no infravermelho.

Os espectrofotômetros atualmente utilizados na espectroscopia de absorção no infravermelho são baseados em princípios interferométricos e não mais em elementos dispersivos como os utilizados na década de 70. A inserção do interferômetro de Michelson na óptica dos espectrofotômetros permite maior resolução e qualidade espectral com o aumento da razão sinal-ruído e maior velocidade de varredura e aquisição de espectros [22].

No interferômetro de Michelson, um beamsplitter divide o feixe de radiação infravermelha em dois e direciona parte destes a um braço com um espelho fixo e o outro para um braço com um espelho móvel. Após a reflexão nos espelhos, ambos os feixes voltam 
a se combinar e de acordo com a diferença de fase causada pelos diferentes caminhos ópticos que estes percorreram, os mesmos podem interagir construtivamente ou destrutivamente $[22]$.

A Figura 3 ilustra o funcionamento dos espectrofotômetros com transformada de Fourier. A radiação emitida por uma fonte no infravermelho passa por um interferômetro antes de incidir na amostra. A radiação não absorvida pela amostra incide em um detector, e é gerado um interferograma que mostra a intensidade da radiação detectada em função do deslocamento "x" do espelho móvel [22].

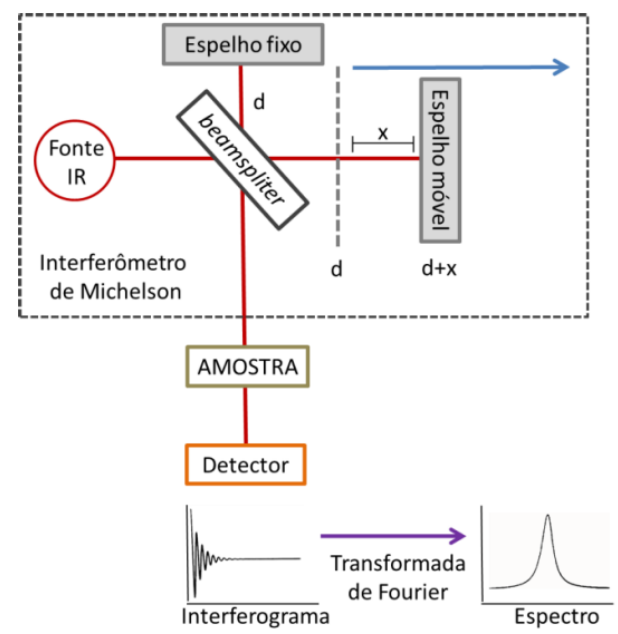

Figura 3. Esquema de funcionamento de um espectrofotômetro FTIR [26]

Obtém-se o espectro de absorção no infravermelho aplicando-se a transformada de Fourier no interferograma coletado, o qual apresenta o número de onda $(\tilde{v})$ da radiação absorvida na forma de bandas:

$$
\tilde{v}=\frac{1}{\lambda} \quad \text { Equação } 1
$$

onde $\lambda$ é o comprimento de onda dado em $\mathrm{cm}$ e $\tilde{\boldsymbol{v}}$ o número de onda $\mathrm{em}^{-1}$ [23].

A configuração experimental para aquisição de espectros FTIR pode ser feita de diferentes maneiras, dentre estas as mais utilizadas são a transmissão, transflexão e reflexão total atenuada (ATR) [27] (Figura 4). 
(A)

Transmissão

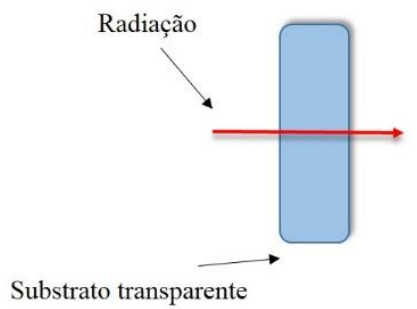

(B)

\section{Transflexão}

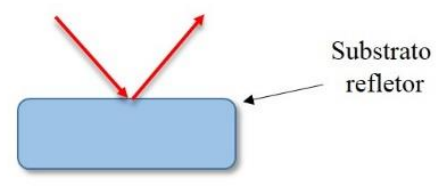

(C) Reflexão total atenuada

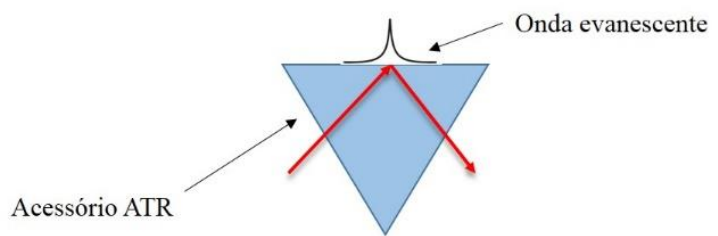

Figura 4. Principais configurações experimentais utilizadas na obtenção de espectros FTIR [27,28].

No modo de transmissão os espectros são adquiridos a partir da radiação não absorvida pela amostra (radiação transmitida). Para isto, faz-se necessário que a amostra seja depositada em substrato transparente à radiação no infravermelho (Figura 4A), uma vez que as lâminas de vidro comum possuem modos vibracionais ativos no infravermelho que irão contribuir no espectro coletado. Os substratos comumente usados são pastilhas de Brometo de Potássio $(\mathrm{KBr})$ e/ou janelas de Fluoreto de Bário $\left(\mathrm{BaF}_{2}\right)$, Fluoreto de Cálcio $\left(\mathrm{CaF}_{2}\right)$ e Seleneto de Zinco (ZnSe), dentre os quais as pastilhas de $\mathrm{KBr}$ são as mais utilizadas devido ao alto custo comercial das demais janelas. A deposição de amostras em substratos exigem um método de preparação padronizado e delicado, no qual deve-se evitar a formação de bolhas de ar e outros efeitos particulares ao tipo de material estudado [29]. Além disso, os espectros obtidos via transmissão estão sujeitos a uma variedade de efeitos físicos que ocorrem simultaneamente a absorção e devem ser corrigidos computacionalmente [30-33].

$\mathrm{Na}$ transflexão a amostra é depositada em um substrato refletor, de maneira que a radiação incidente interaja com a amostra e seja refletida pelo substrato de volta para a mesma. (Figura 4B). Os principais substratos utilizados são as lâminas de baixa emissividade (Low-E), constituídas por uma lâmina de vidro recoberta com camada de $\mathrm{Ag} / \mathrm{SnO}_{2}$ [34]. Ao contrário das janelas utilizadas no modo de transmissão, os substratos para transflexão não são caros, porém, contribuem para a formação de uma onda estacionária perpendicular à 
superfície da amostra que conduz alterações espectrais não relacionadas a bioquímica da amostra estudada [35-38].

Na configuração experimental via reflexão total atenuada (ATR) a amostra é colocada sobre um elemento de reflexão interna com índice de refração superior ao do material, induzindo a reflexão interna total da radiação incidente, a qual é atenuada e penetra na amostra como uma onda evanescente (Figura 4C) [28]. O elemento de reflexão interna pode

ser um diamante, ZnSe, Germânio ou Silício. A penetração da radiação $\left(d_{p}\right)$ na amostra é particular a cada comprimento de onda $(\lambda)$ e depende do índice de refração da amostra $\left.n_{2}\right)$, do índice de refração do elemento de reflexão interna $\left(n_{1}\right)$ e do ângulo de incidência da radiação $(\theta)$, como mostrado na equação 1 [39].

$$
d_{p}=\frac{\lambda / n_{1}}{2 \pi \sqrt{\left[\operatorname{sen} \theta-\left(\frac{n_{1}}{n_{2}}\right)^{2}\right]}}
$$

Equação 1

Ao contrário da transmissão e transflexão, medidas no ATR não requerem de substratos especiais e pouco ou nenhum preparo da amostra, necessitando apenas que o material estudado (sólido ou líquido) seja colocado em contato direto com o elemento de reflexão interna. Diante disso, os artefatos de dispersão espectral mencionados anteriormente não são observados, tornando o processo de análise mais rápido e simples [27]. Adicionado a isso, o modo ATR-FTIR possibilita o acoplamento de fibra óptica (FTIR-FEW, Fourier Transform Infrared evanescent wave fiberoptical), possibilitando que espectros possam ser obtidos diretamente da amostra, em particular, diretamente na pele do paciente como ferramenta auxiliar no diagnóstico de distúrbios dermato-patológicos [40,41].

\subsection{Espectroscopia FTIR como ferramenta diagnóstica de neoplasias}

O diagnóstico precoce de câncer é fundamental para alcançar um tratamento com resultados favoráveis e diminuir o índice de mortalidade causado pela doença na sociedade. Contudo, até o momento não há um método preciso e confiável para detecção da doença em estágios iniciais. Desenvolvimentos nas tecnologias de imageamento médico, como ultrasonografia, tomografia computadorizada e ressonância magnética, têm melhorado a 
qualidade, sensibilidade e rapidez do diagnóstico de câncer. Tais métodos permitem localizar e informam a dimensão do tumor, no entanto não são suficientes para determinar a presença de malignidade. O método padrão ouro para discriminar tecidos normais e alterados ainda é a análise histopatológica [42], de forma que a busca por técnicas complementares e novos métodos de diagnóstico tem se tornado uma área ativa e promissora.

Dentre as técnicas atualmente estudadas como possíveis ferramentas de diagnóstico precoce, a biópsia óptica, representada por técnicas fotônicas, tem obtido grande sucesso na caracterização de materiais com origem biológica. A espectroscopia vibracional, constituída pelas técnicas de espalhamento Raman e FTIR, são de especial interesse devido a sua alta sensibilidade na detecção de alterações bioquímicas e moleculares em tecidos biológicos, colaborando para o surgimento de uma nova modalidade científica: a Espectro-histopatologia (SHP, Spectral histopathology) [7-13].

Em particular, a região do infravermelho médio obtida com a espectroscopia FTIR (400-4000 $\mathrm{cm}^{-1}$ ) compreende modos vibracionais associados a importantes componentes bioquímicas celulares, podendo ser utilizados como marcadores na identificação de alterações metabólicas sofridas pela célula durante o processo de carcinogênese.

Alterações significantes em modos vibracionais associados a ácidos nucleicos, proteínas e lipídios foram observadas em diversos trabalhos que utilizaram a espectroscopia FTIR para analisar as mudanças bioquímicas em tecido normal causadas por diferentes tipos de neoplasia [43-53]). Ácidos nucleicos, proteínas e lipídios são macromoléculas construídas com precursores relativamente simples e representam toda a parte orgânica que forma uma célula. Devido a importância dessas moléculas como possíveis marcadores para o diagnóstico de tumores, descreveremos a seguir aspectos básicos da bioquímica estrutural das mesmas.

\subsubsection{Proteínas [54]}

As proteínas são as macromoléculas mais abundantes nas células vivas e são encontradas em todas as células e partes das mesmas. São formadas por aminoácidos dispostos linearmente em cadeia, unidos por ligações peptídicas. Uma molécula de aminoácido é formada por um átomo de carbono central (carbono alfa) ligado a um grupo 
carboxila $(\mathrm{COOH})$, um grupo amina $\left(\mathrm{NH}_{2}\right)$, um átomo de hidrogênio e um quarto grupo genérico que é particular a cada aminoácido (radical R) como mostrado na Figura 5.

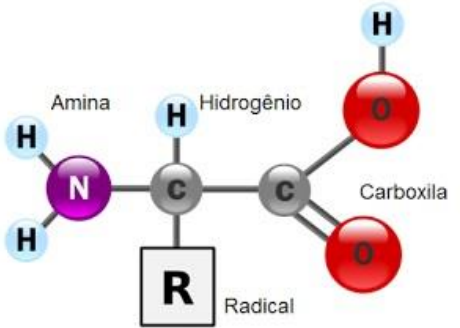

Figura 5. Estrutura geral de um aminoácido [55].

A ligação peptídica entre aminoácidos vizinhos em uma molécula de proteína é estabelecida sempre entre o grupo amina de um aminoácido com o grupo carboxila de outro (Figura 6).

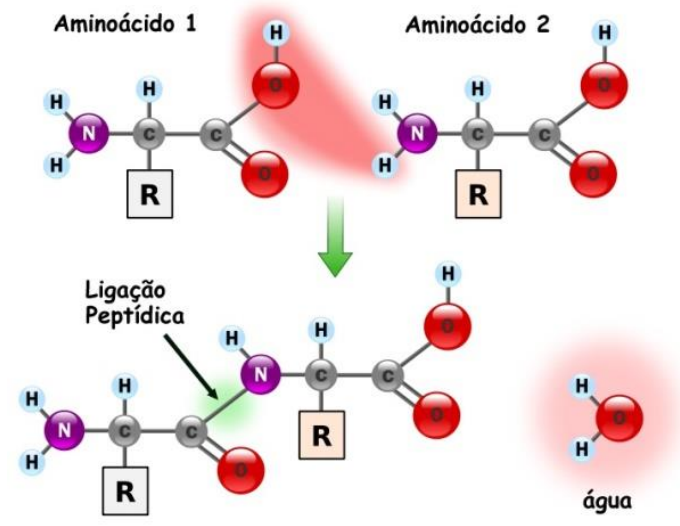

Figura 6: Ligação peptídica entre dois aminoácidos [55]

A maioria das proteínas encontram-se em estruturas únicas tridimensionais. A forma a qual uma proteína naturalmente se encontra é conhecida como seu estado nativo. Há quatro tipos distintos de estrutura proteica, conforme apresentado na Figura 7. 


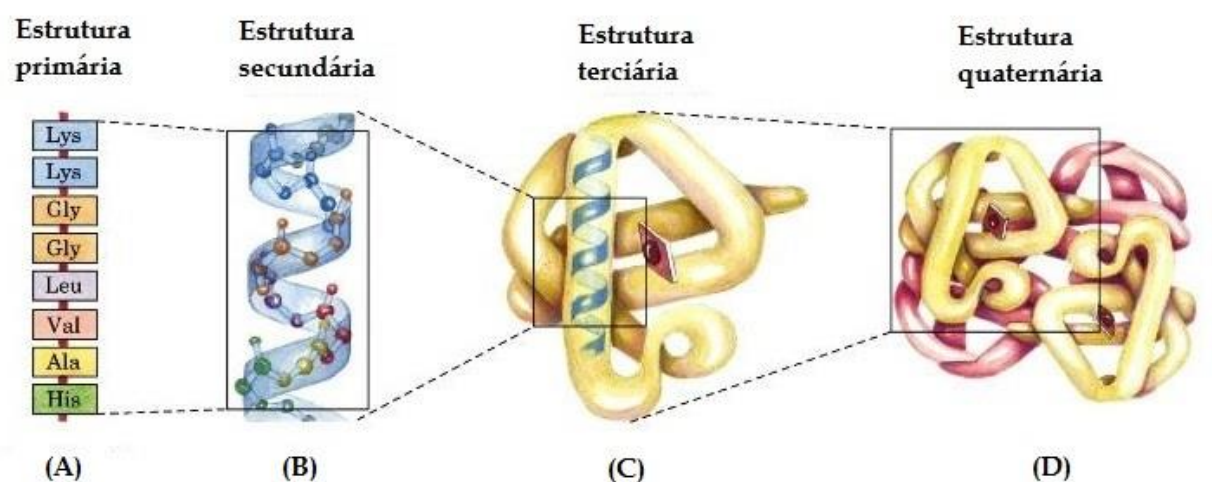

Figura 7. Esquema das estruturas de proteínas.

A estrutura primária consiste na sequência de aminoácidos unidos via ligação peptídica. Na natureza são encontrados 20 tipos de aminoácidos e a maneira que os mesmos se associam pode produzir proteínas com propriedades e atividades distintas. A repetição regular da sequência de aminoácidos que formam a estrutura primária dá origem a estrutura secundária, cujo exemplos mais comuns são a $\alpha$-hélice e folha- $\beta$ (Figura 8).

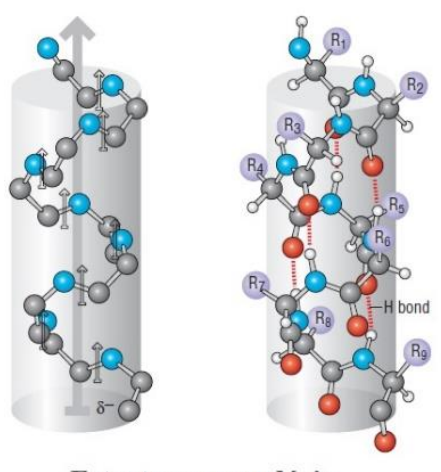

Estrutura secundária $\alpha$-hélice

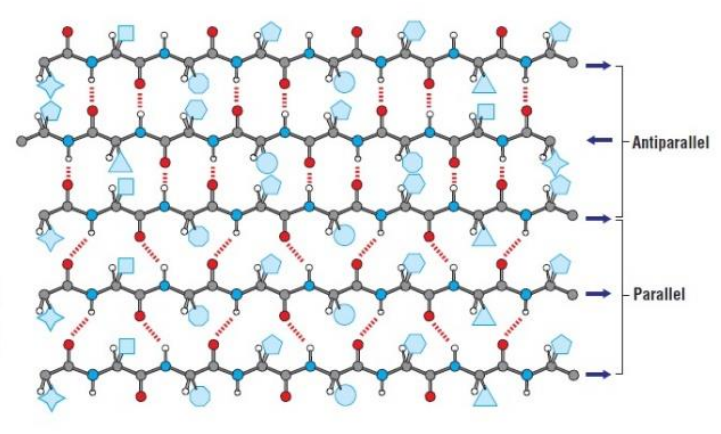

Estrutura secundária folha- $\beta$

Figura 8. Principais estruturas secundárias encontradas em proteínas [56]

Na estrutura secundária do tipo $\alpha$-hélice, a cadeia polipeptídica é retorcida em torno de um eixo imaginário que passa pelo centro da hélice, de forma que os grupos $\mathrm{R}$ de cada aminoácido projetam-se para a face externa da hélice. A formação de tal estrutura se deve a pontes de hidrogênio entre o átomo de hidrogênio do grupo amina $(\mathrm{N}-\mathrm{H})$ (bolinhas brancas na Figura 8A) com o átomo de oxigênio do radical carboxila (bolinhas vermelhas na Figura 8A). A conformação folha- $\beta$ de proteínas (Figura 8B) é formada quando cadeias 
polipeptídicas dispõem-se lado a lado em ziguezague e são estabilizadas por pontes de hidrogênio entre aminoácidos de cadeias vizinhas e não entre aminoácidos da mesma cadeia como na estrutura $\alpha$-hélice. De acordo com a orientação das cadeias polipeptídicas, a estrutura folha- $\beta$ pode ser paralela ou antiparalela. Na estrutura paralela os aminoácidos organizam-se de maneira que os grupos amina e carboxila repitam-se periodicamente e paralelamente entre duas cadeias ligadas. Enquanto que na folha- $\beta$ antiparalela estes se distribuem de maneira que o grupo amina de uma cadeia seja adjacente ao grupo carboxila da cadeia vizinha. Tal fato resulta em pontes de hidrogênio mais estáveis para configurações antiparalelas, visto que as mesmas são mais lineares que na estrutura paralela como mostrado na Figura 8B.

\subsection{2. Ácidos Nucleicos [54]}

Os ácidos nucléicos (DNA e RNA) são fundamentalmente formados por unidades básicas chamadas nucleotídeos, os quais são constituídos por uma molécula de açúcar com cinco carbonos (pentose), ligada a uma base nitrogenada e um ou mais grupos fosfatos (Figura 9).

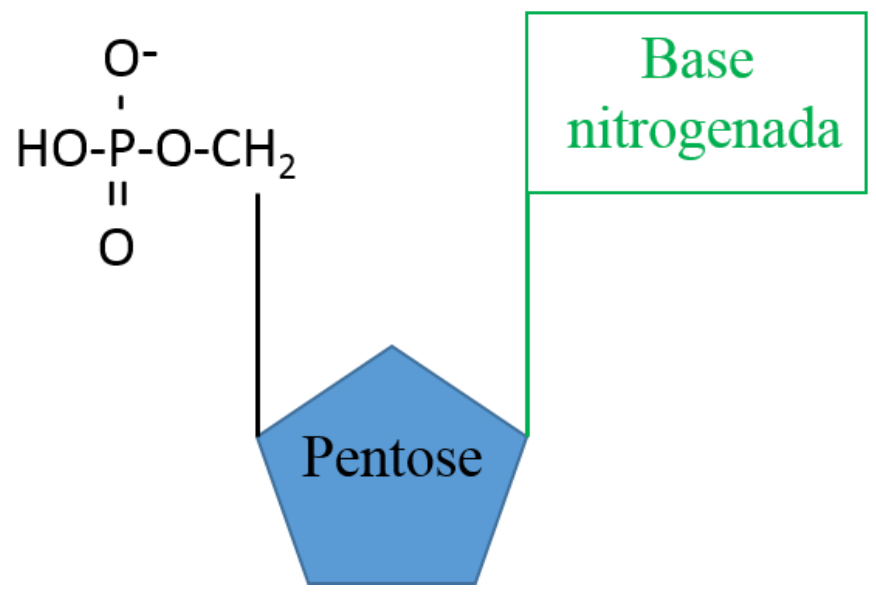

Figura 9. Estrutura de um nucleotídeo

A ligação entre nucleotídeos ocorre diante uma ligação covalente do tipo fosfodiéster, caracterizada pela ligação do fosfato de um nucleotídeo ao grupo hidroxila de um nucleotídeo vizinho (Figura 10). 


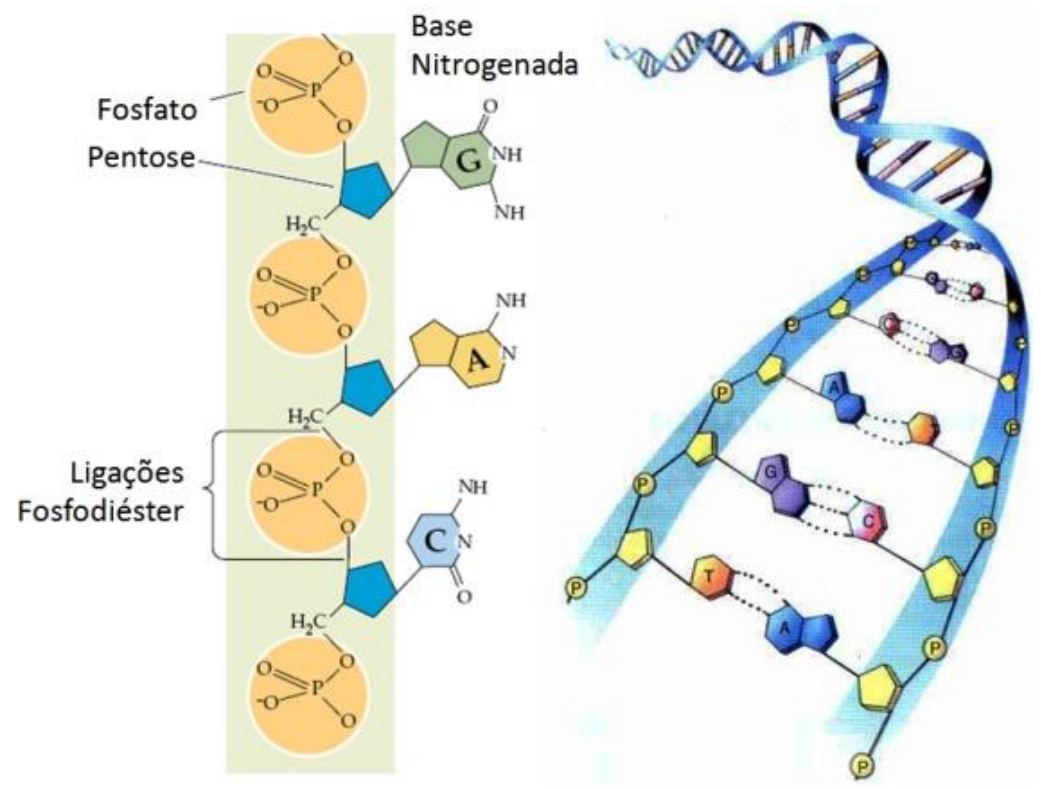

Figura 10: Ligações de nucleotídeos

Existem dois tipos de ácidos nucleicos: o ribonucleico ou RNA (ribonucleic acid) e o desoxirribonucleico ou DNA (deoxyribonucleic acid), que diferem entre si quanto ao tipo de açúcar presente em suas estruturas (ribose no RNA e desoxirribose para o DNA).

A sequência linear dos nucleotídeos no DNA e RNA codificam a informação genética das células. A estrutura de cada proteína e, em última análise, cada biomolécula e componente celular é um produto da informação programada na sequência nucleotídica dos ácidos nucleicos da célula.

\subsubsection{Lipídios [54]}

Define-se como lipídios o conjunto de moléculas biológicas que são insolúveis em água e solúveis em solventes orgânicos. Caracteristicamente, estes contêm ou uma longa cadeia hidrocarbonatada (ácidos graxos) ou então são compostos por múltiplos anéis aromáticos (esteróis).

Os ácidos graxos são compostos por duas regiões quimicamente distintas: uma é composta por uma longa cadeia hidrocarbonatada (que é hidrofóbica) e a outra é composta por um grupo carboxila $\mathrm{COOH}$ (hidrofílico), o qual permite que os ácidos graxos se liguem covalentemente a outras moléculas celulares. Quando duas ou três moléculas de ácidos graxos se unem a uma molécula de glicerol, formam-se os glicerídeos (Figura 11). 


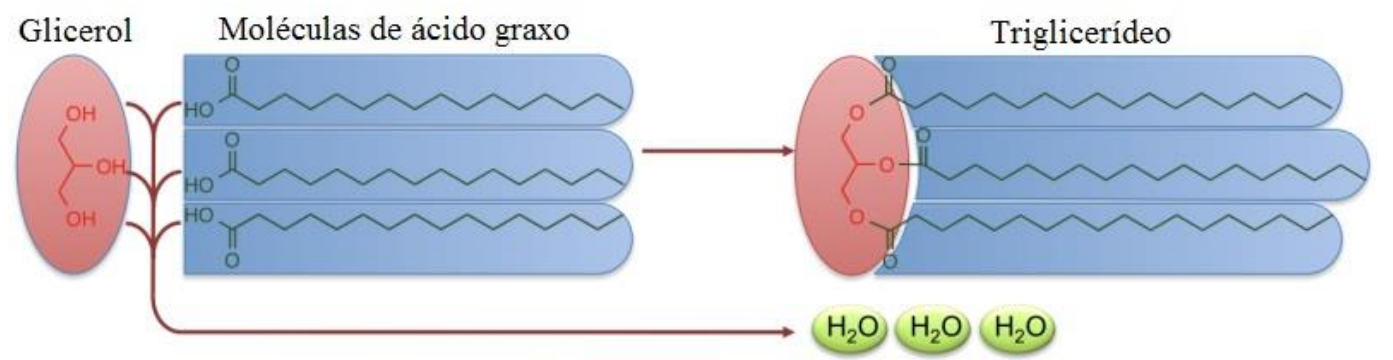

Figura 11. Formação de molécula de glicerídeo triplo (triglicerídeo) a partir de três ácidos graxos e uma molécula de glicerol [57]

Os ácidos graxos exercem a função de reserva energética celular, de maneira que a degradação dos mesmos produz aproximadamente seis vezes mais energia que a obtida com moléculas de glicose. Na forma de triglicerídeos, os ácidos graxos são armazenados no citoplasma celular como gotículas moleculares.

A função mais importante dos ácidos graxos consiste em servir de base para construção da camada fosfolipídica das membranas celulares. Uma molécula de fosfolipídio resulta da união de duas moléculas de ácido graxo ligadas a dois sítios de um glicerol, que tem seu terceiro sítio ligado a um grupo fosfato (Figura 12).
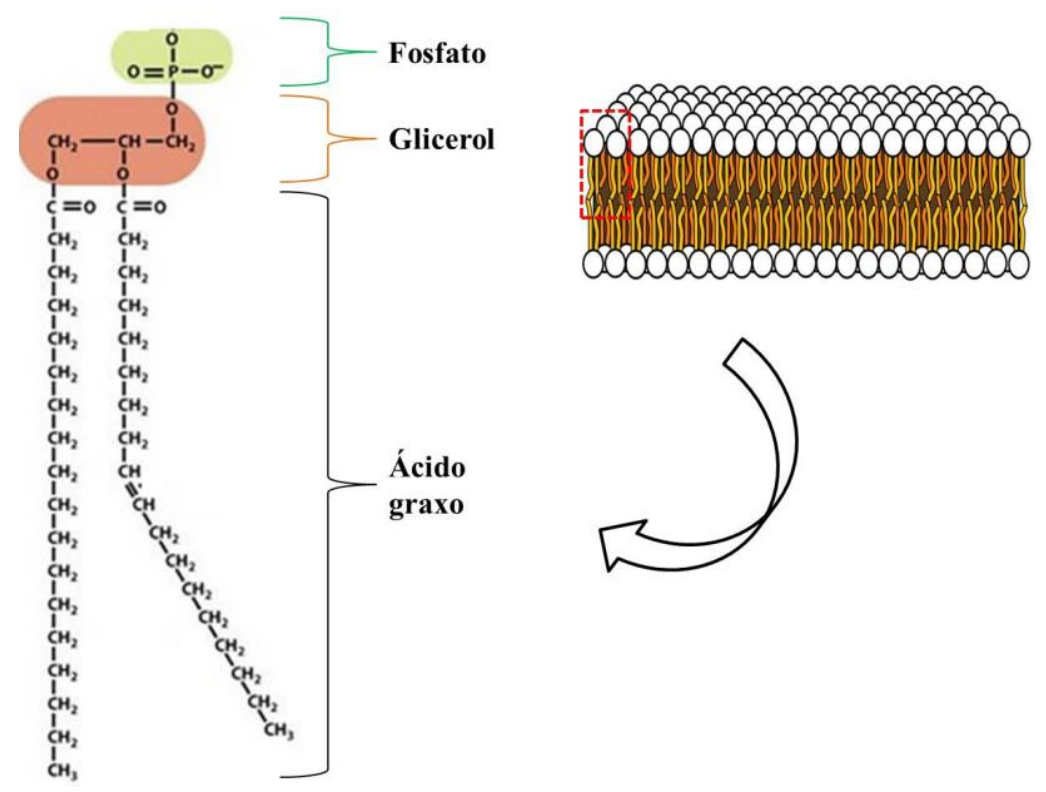

Figura 12. Molécula de fosfolipídio à esquerda e bicamada fosfolipídica à direita. (Adaptado de [54]) 
As membranas biológicas são formadas por fosfolipídios organizados em camadas duplas, nas quais se incrustam proteínas e outras moléculas importantes ao metabolismo celular. 


\section{Material e Métodos}

\subsection{Preparação de amostras}

As amostras utilizadas neste trabalho foram obtidas em experimento realizado no período de 2010-2012 durante uma dissertação de mestrado [58]. Após aprovação do Comitê de Ética em Pesquisa Animal do IPEN, parecer no71/10-CEUA-IPEN/SP (Em anexo), 50 camundongos fêmeas da raça swiss tiveram o dorso tricotomizado e submetido a indução de carcinoma espinocelular cutâneo via carcinogênese química.

O protocolo de tumorigênese utilizado possui duas fases: iniciação e promoção [59]. Na primeira fase os animais tiveram o dorso instilado com dose única de $50 \mu \mathrm{g}$ de DMBA (7,12-dimetil-enzantraceno) diluídos em $100 \mathrm{ml}$ de acetona. Após uma semana iniciou-se a fase de promoção, na qual $5 \mu \mathrm{g}$ de TPA (12-O-tetradecanoil-forbol-13 acetato) diluídos em $200 \mathrm{ml}$ de acetona foram aplicados duas vezes por semana em um período total de sete meses (Figura 13). Os animais do grupo controle receberam apenas aplicações de acetona e todo o procedimento de aplicação foi realizado em uma capela de fluxo laminar para garantir a segurança do manipulador.
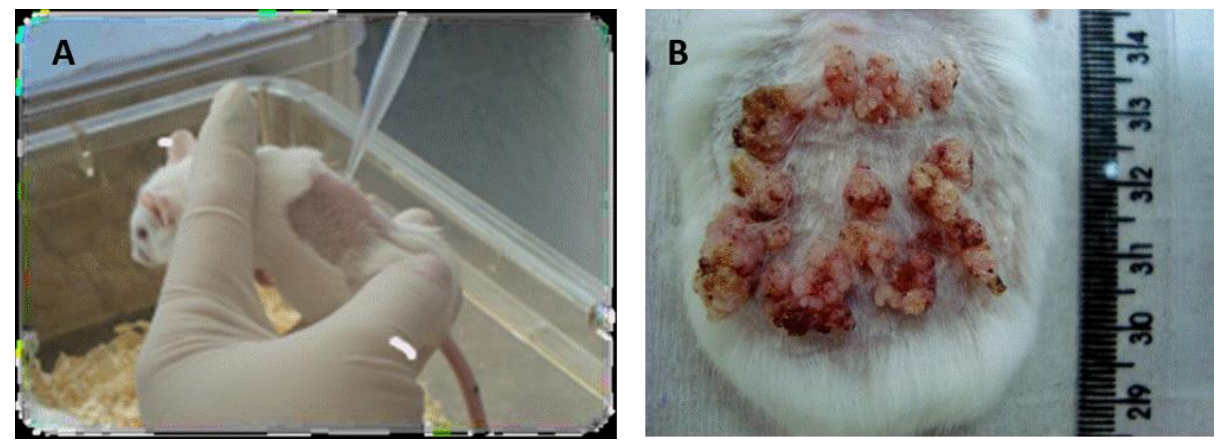

Figura 13. Instilação de carcinógenos em camundongo tricotomizado (A). Nódulos tumorais obtidos após sete meses de carcinogênese (B) [58].

Após um período de vinte e oito semanas obteve-se animais com nódulos de tumores visíveis como mostrado na Figura 13. O longo tempo de indução e o estado debilitado que o tumor causa nos animais resultou no óbito de $50 \%$ do número inicial.

Ao fim da carcinogênese química os animais foram eutanasiados via overdose de anestésicos seguida de exposição à mistura de gases $\left(\mathrm{O}_{2}\right.$ e $\left.\mathrm{CO}_{2}\right)$, e tiveram o dorso extraído 
via biópsia. Os tecidos obtidos foram fixados com formaldeído por 24 horas e posteriormente diafanizados em dois banhos de xilol puro por 30 minutos e desidratados em banhos de etanol com concentrações crescentes (50, 70 e 100\%). Ao fim da desidratação, os tecidos obtidos foram incluídos em parafina e mantidos em dissecador para análise posterior.

A partir dos blocos parafinizados, cortes sequenciais com $5 \mu \mathrm{m}$ de espessura foram obtidos via micrótomo e depositados em lâminas de vidro comum para análise histopatológica e lâminas de baixa emissividade (MirrIR low E-coated glass, Kevley tecnologies) para análise espectroscópica. Neste trabalho as amostras utilizadas provém de camundongos do grupo controle e de animais submetidos a carcinogênese química, como descrito na Tabela 1. Descrição dos grupos experimentais

Tabela 1. Descrição dos grupos experimentais

\begin{tabular}{ccc}
\hline Grupo & Tratamento & Descrição \\
\hline Grupo 1 $(\mathrm{N}=13)$ & Controle & Pele sadia \\
Grupo 2 $(\mathrm{N}=13)$ & Neoplasia & Tecido tumoral \\
\hline
\end{tabular}

\subsection{Aquisição de espectros}

Os espectros de absorção no infravermelho foram obtidos com um espectrofotômetro do tipo interferométrico (Nicolet 6700, Thermo Scientific $®$ ) acoplado a um acessório de reflexão total atenuada (Smart Orbit, Thermo Scientific ${ }^{\circledR}$ ) com um diamante de índice de refração igual a 2,4 como elemento de reflexão interna. Os dados foram adquiridos no intervalo de 4000-400 $\mathrm{cm}^{-1}$ (infravermelho médio) usando-se uma fonte infravermelha do tipo Glowbar, um detector DTGS (deuterated triglycine sulphate) e divisor de feixe de $\mathrm{KBr}$ recoberto com germânio. Cada espectro coletado resulta da média de 100 varreduras com resolução espectral de $4 \mathrm{~cm}^{-1}$ e corresponde a um ponto da lâmina posicionada sobre o diamante do ATR como mostrado na Figura 14. 

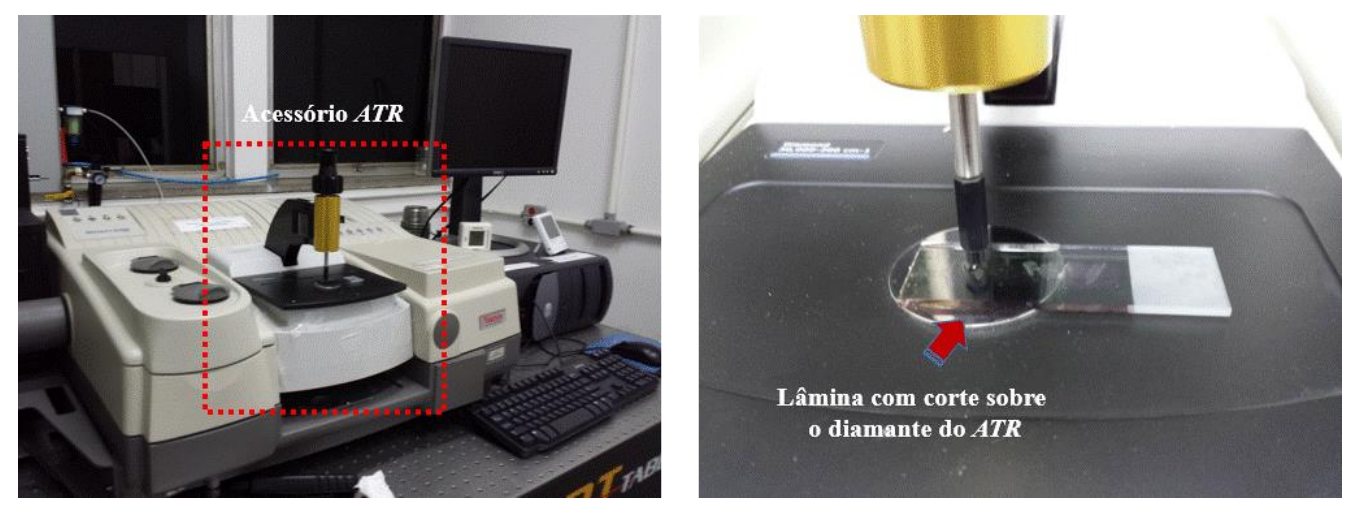

Figura 14: Espectrofotômetro FTIR acoplado à acessório ATR (à esquerda); Corte histológico sobre o diamante do ATR (à direita)

Coletou-se aproximadamente 10 espectros por lâmina, os quais foram obtidos em diferentes pontos do tecido através de uma varredura visual, como mostrado na Figura 15.
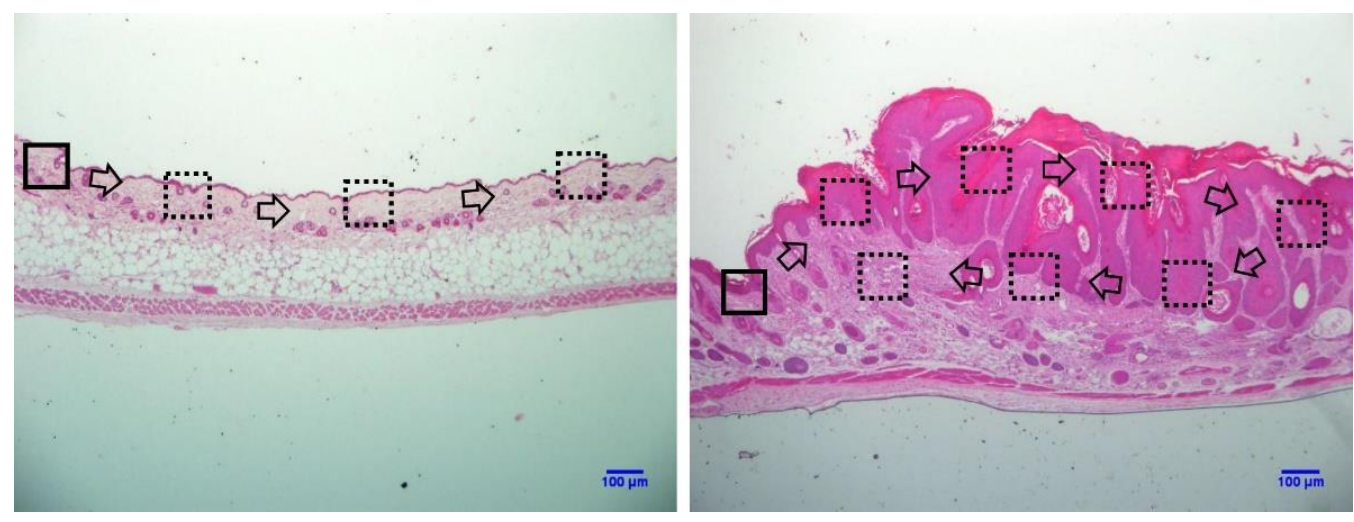

Figura 15: Varredura efetuada em cada corte durante a aquisição de espectros.

Os espectros foram exportados como arquivo de texto e analisados posteriormente com auxílio dos softwares Origin Pro 8.0, Minitab 17 e Matlab R2013a (Mathworks ${ }^{\circledR}$, Natick, MA, USA).

\subsection{Desparafinização das lâminas}

Para obter cortes delgados e precisos necessita-se incluir os tecidos biológicos em meios que ofereçam sustentação durante o corte, que pode ser via congelamento (cortes criogênicos) ou através de algum meio de inclusão (parafina, historesina, ...) [60]. Como mencionado no tópico 4.1, o presente trabalho utilizou a parafina como meio de inclusão, a qual é um composto orgânico formado por longas cadeias abertas de hidrocarbonetos e assim 
como grande parte dos compostos de carbono, apresenta modos vibracionais ativos e bem definidos na região do infravermelho médio, ocasionando a inibição das bandas provenientes do tecido biológico (Figura 16).

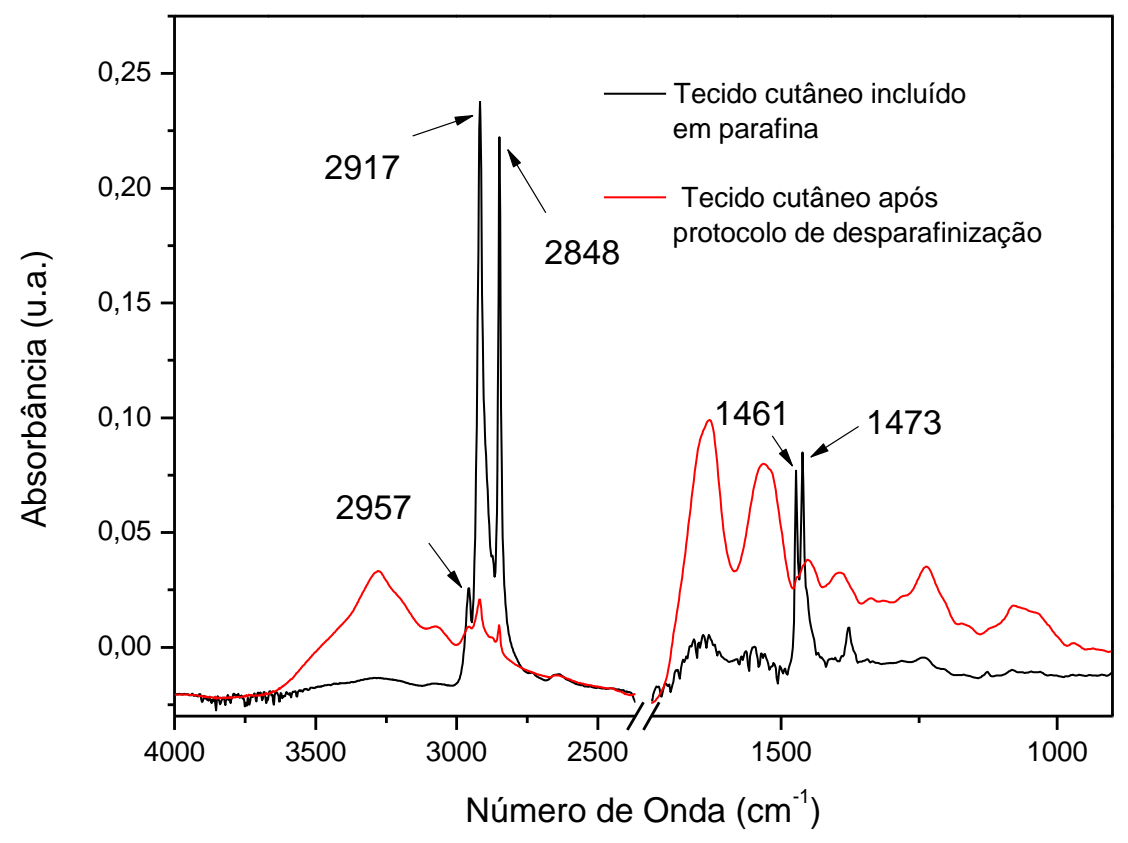

Figura 16. Espectro de absorção no infravermelho de lâmina com parafina

Devido a sobreposição dos picos da parafina com os modos vibracionais do tecido biológico, faz-se necessário remover os mesmos antes de qualquer técnica de análise.

Alguns espectroscopistas optam pela remoção matemática das bandas associadas à parafina, evitando que as amostras sejam submetidas a solventes orgânicos que possam alterar suas estruturas [61,62]. Contudo, a desparafinização digital é ainda contestada, visto que os algoritmos aos quais os espectros são submetidos podem alterar não só os picos da parafina como também aqueles provenientes do tecido biológico [63]. Byrne e colaboradores mostraram que a desparafinização utilizando hexano e xileno como solventes não removem completamente a parafina [64]. Contudo, em trabalho posterior, Rehman et al propuseram um protocolo de desparafinização para espectroscopia de espalhamento Raman, no qual obtiveram total remoção dos picos da parafina sem alterar as bandas associadas ao tecido biológico [65]. 
Baseando-se no protocolo proposto por Rehman, as amostras deste trabalho foram submetidas a dois banhos de xilol (Sigma Aldrich, número CAS: 247642) durante 10 minutos cada e posteriormente imersas em álcool puro (Sigma Aldrich, número CAS: 459844) por cinco minutos.

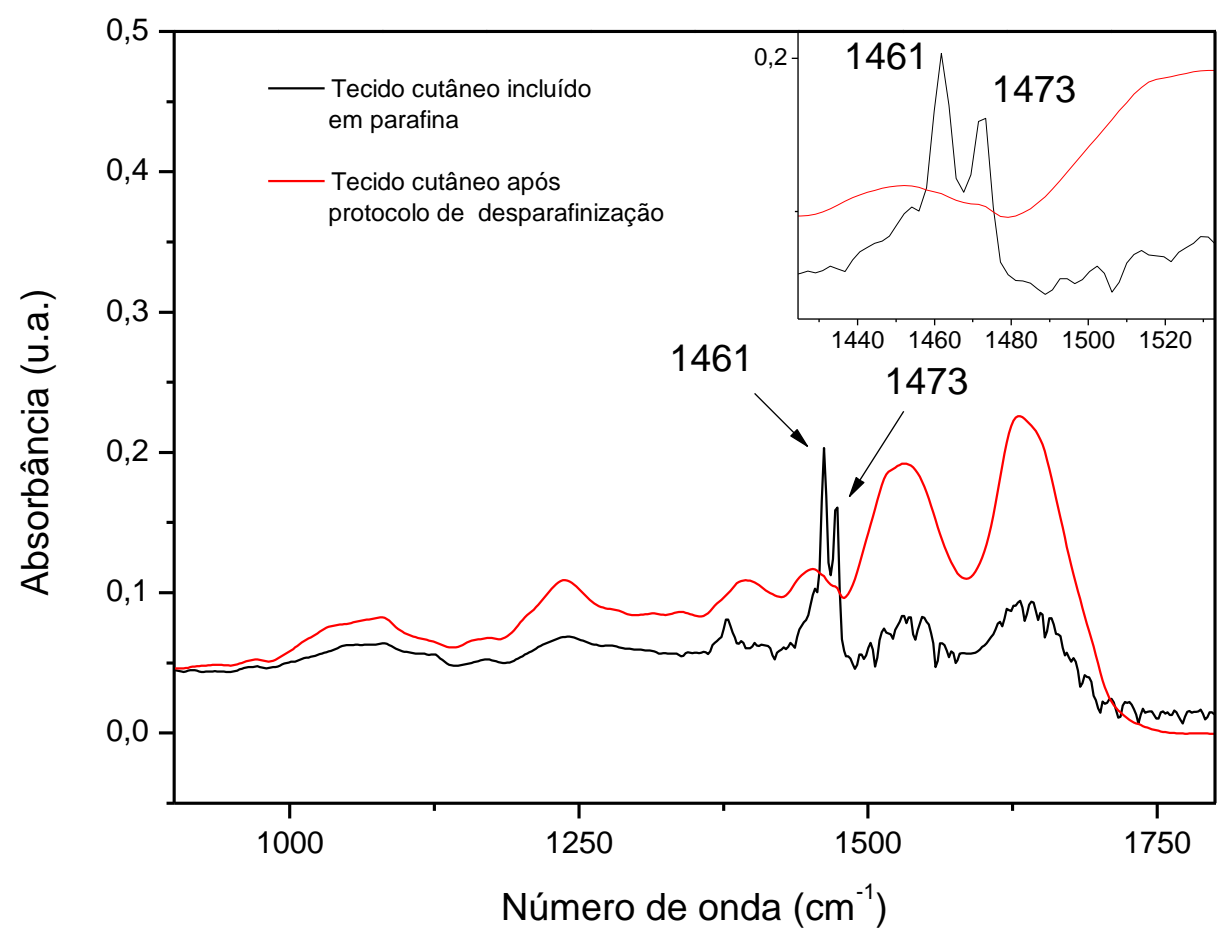

Figura 17. Espectros FTIR de tecido cutâneo antes (linha preta) e após (linha vermelha) protocolo de desparafinização

As figuras 16 e 17 mostram que o protocolo de desparafinização foi suficiente para remover as bandas associadas à parafina, uma vez que os modos vibracionais em $1461 \mathrm{e}$ $1473 \mathrm{~cm}^{-1}$ não são observados no espectro após a desparafinização (Figura 17), enquanto as bandas da parafina em altos números de onda $\left(2957,2917\right.$ e $\left.2848 \mathrm{~cm}^{-1}\right)$ sofreram considerável redução. Contudo, como descrito na seção 3.3.3, substâncias lipídicas são solúveis em solventes orgânicos e consequentemente, são também afetadas pelo xilol utilizado para remover a parafina [66]. Gardner e colaboradores afirmam que o uso de xilol como solvente remove apenas substâncias lipídicas livres e sugerem que a interpretação bioquímica de 
modos vibracionais em tal região (2800-3200 $\mathrm{cm}^{-1}$ ) seja atribuída especificamente a complexos lipídicos ligados a outras estruturas [63]. Nesse contexto, considerando que não há trabalhos na literatura que sustentem a proposta de Gardner e descrevam o grau de alterações causadas a lipídios com solventes orgânicos, o presente trabalho direcionou-se a análise espectroscópica da região de impressão digital (fingerprint region) (900-1800 cm¹).

\subsection{Normalização Vetorial}

Para que os espectros possam ser comparados uns aos outros é necessário que os mesmos sejam normalizados antes de qualquer análise. Neste trabalho utilizou-se a normalização vetorial, a qual é obtida conforme as seguintes equações:

$$
\begin{array}{ll}
y_{m}=\frac{\sum_{i} y_{i}}{i} & \text { Equação 2 } \\
y^{\prime}(i)=y(k)-y_{m} & \text { Equação 3 } \\
y^{\prime \prime}(i)=\frac{y^{\prime}(i)}{\sqrt{\sum_{i}\left(y^{\prime}(i)\right)^{2}}} & \text { Equação 4 } \\
\sum_{i}\left(y^{\prime \prime}(i)\right)^{2}=1 & \text { Equação 5 }
\end{array}
$$

onde $y_{m}$ é a média da absorbância obtida em cada número de onda (Equação 2), $y^{\prime}(i)$ é o valor original da absorbância de cada ponto subtraído da média calculada (Equação 3) e $y^{\prime \prime}(i)$ são os novos valores obtidos para cada ponto do espectro original. Ao fim da normalização, a soma dos quadrados dos valores obtidos deve ser igual a um, como mostrado na Equação 5 [67].

A Figura 18 mostra espectros de uma mesma amostra antes e após normalização vetorial. 

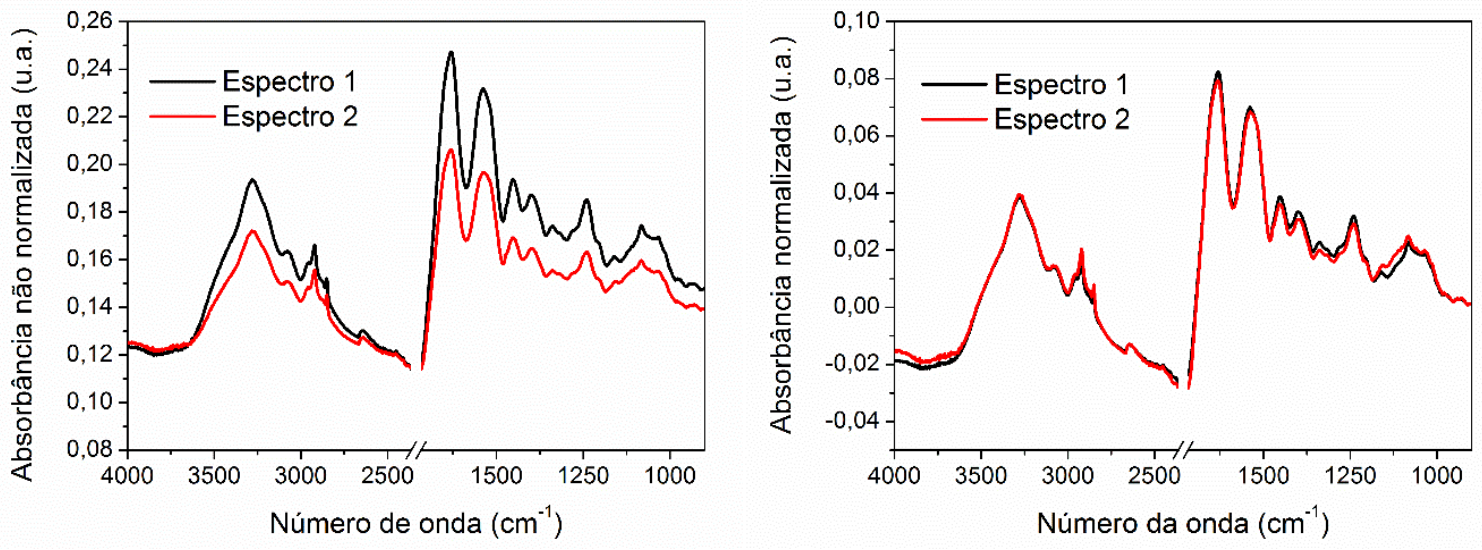

Figura 18: Espectros obtidos de uma mesma região em uma amostra antes e depois da normalização vetorial: não normalizados (à esquerda) e normalizados vetorialmente (à direita)

\subsection{Derivada de segunda ordem e filtro de Savitzky-Golay}

Devido à proximidade dos números de onda nas quais determinado modo vibracional absorve, frequentemente ocorre a sobreposição de bandas em espectros FTIR. De acordo com a intensidade e proximidade destas bandas as mesmas podem se apresentar na forma de ombros fracamente intensos, dificultando a visualização e identificação das mesmas. Visando evidenciar a posição exata das bandas sobrepostas e reduzir os efeitos quadráticos da linha de base causados por partículas espalhadoras [68], calculou-se a derivada de segunda ordem para cada espectro, uma vez que tal ferramenta matemática maximiza pontos onde exista uma inclinação/concavidade da função estudada.

A Figura 19 simula a sobreposição de bandas que podem ocorrer em um espectro de absorção no infravermelho. Na Figura 19A duas funções gaussianas aleatórias G1 e G2 (linhas azul e vermelha) foram geradas, assim como a função resultante da sobreposição das mesmas, G1+G2 (em preto). A Figura 19B mostra a derivada das funções inicialmente obtidas, e no caso de funções gaussianas, os máximos das funções iniciais (a média da gaussiana) tornam-se mínimos na segunda derivada (vales). 

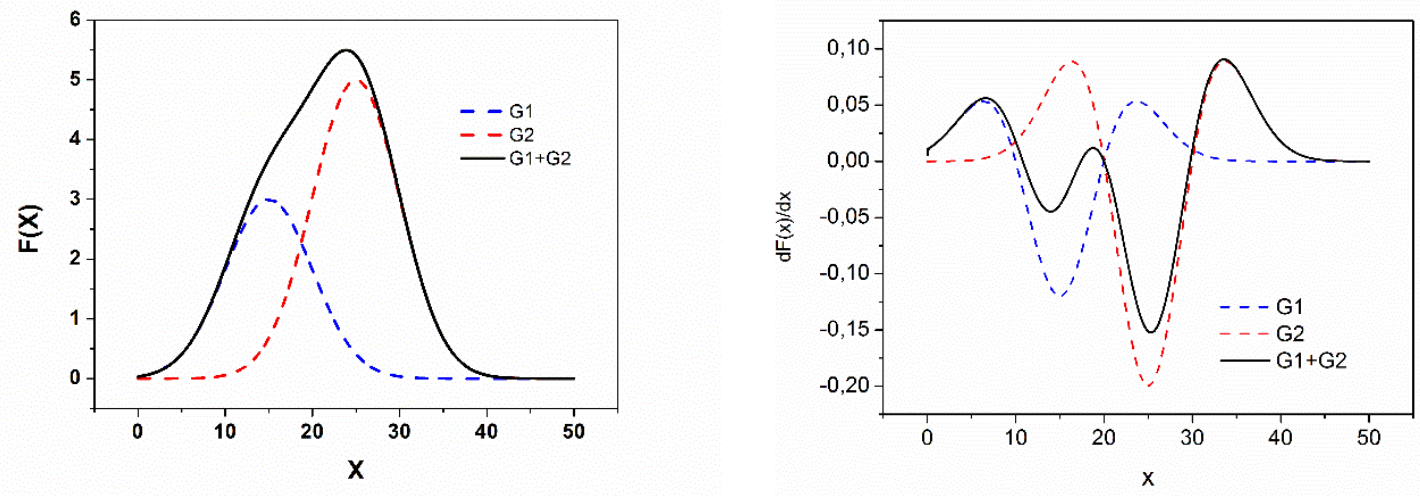

Figura 19. Simulação de banda resultante $(\mathrm{G} 1+\mathrm{G} 2)$ da sobreposição de duas gaussianas G1 e G2 (à esquerda) e segunda derivada das funções simuladas (à direita)

Analisando a Figura 19B, nota-se que os vales obtidos para a função resultante $(\mathrm{G} 1+\mathrm{G} 2)$ correspondem aos mínimos das funções que a compõem (G1 e G2). Diante disso, visando obter informação de bandas sobrepostas no espectro puro, todos os espectros abordados neste trabalho foram submetidos a derivada de segunda ordem.

Devido a sensibilidade apresentada pela derivada de segunda ordem na detecção de pontos em que a função apresente inclinações, ruídos e pequenas flutuações causadas por artefatos de técnica também são maximizados, promovendo o surgimento de vales que não representam modos vibracionais.

Para reduzir a presença destes vales que não possuem significância espectroscópica, submeteu-se a segunda derivada de todos os espectros a suavização de Savitzky-Golay, que é largamente empregada em espectroscopia e obedece o seguinte esquema [67]:

1. Define-se a largura do intervalo

2. Define-se o ponto central do intervalo

3. Remove-se o ponto central obtido no passo 1

4. Ajusta-se através do método de mínimos quadrados um polinômio de grau variável aos pontos restantes

5. Utiliza-se o polinômio para estimar o valor do ponto removido

6. Desloca-se o intervalo para o ponto seguinte do sinal original e repete-se o processo anterior 
A escolha do polinômio e da quantidade de pontos por janela para suavização das curvas foi feita testando-se diferentes condições. Por fim, polinômios de ordem dois e janelas com onze pontos mostraram-se eficientes na remoção de ruídos sem alterar os vales associados aos modos vibracionais, sendo então usados em todos os demais espectros.

\subsection{Análise por agrupamento}

A técnica de análise por agrupamento (HCA, Hierarchical Cluster Analysis) têm como objetivo selecionar e classificar dados ou variáveis de determinado sistema em grupos a partir da distância estatística que os mesmos apresentam entre si [69]. Neste trabalho a semelhança dos dados foi obtida considerando-se o coeficiente de correlação como distância estatística e a partir desse ponto, utilizou-se o algoritmo de Ward para classificar os dados em dois grupos (normal e neoplásico), visto que tal método minimiza a variância dos elementos de cada grupo e maximiza a variância entre os grupos. Ao fim do agrupamento, a semelhança entre os dados e os grupos formados são mostrados na forma de um dendograma, que permite avaliar a maneira que os dados foram distribuídos.

A técnica de HCA foi realizada utilizando-se o software Minitab 17 e visando avaliar o melhor método de classificação, a análise por agrupamento foi realizada de duas maneiras: utilizando-se todos os espectros coletados e também o espectro médio obtido para cada corte histológico. 


\section{Resultados}

\subsection{Análise histopatológica}

Considerando a avaliação histopatológica o padrão ouro para o diagnóstico e estadiamento de neoplasias, foi realizado uma análise do perfil histológico de pele sadia e neoplásica, como mostrado na Figura 20.
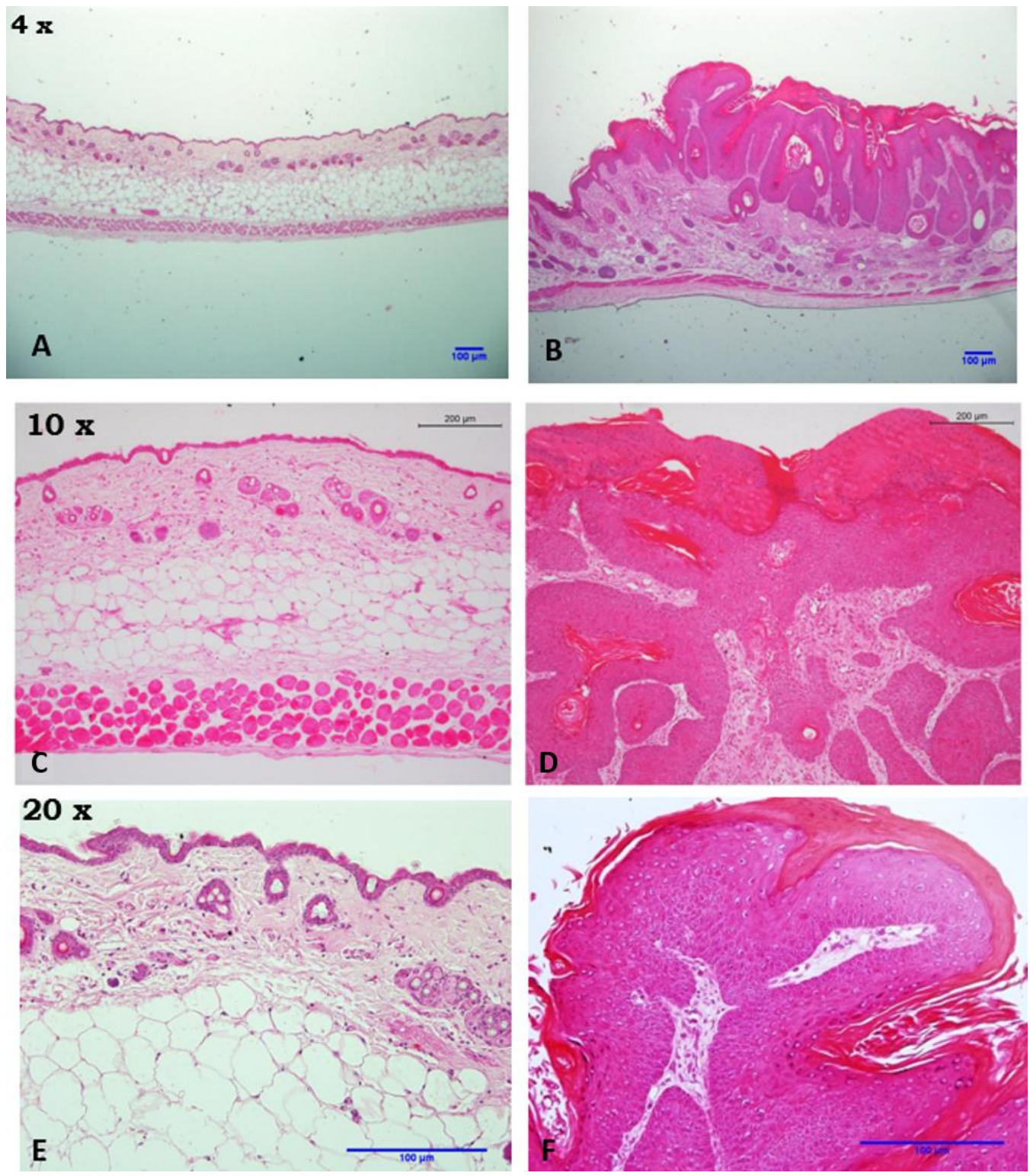

Figura 20. Microscopia de luz de cortes histológicos corados com H\&E. (A) pele saudável; (B) lesão neoplásica em aumento de 4x. (C) pele saudável; (D) lesão neoplásica em aumento de 10x. (E) pele saudável; (F) lesão neoplásica em aumento de 20x 
As características anatomopatológicas apresentadas por ambos os grupos são claramente diferentes. Os cortes histológicos de pele sadia evidenciam epiderme com 3 ou 4 camadas de células cobertas por uma fina camada queratinizada, enquanto as lesões neoplásicas mostraram intensa proliferação de queratinócitos em padrão exofítico cobertos por estrato córneo espesso. Displasia moderada foi observada na camada basal do epitélio das lesões neoplásicas, caracterizada pela presença de intenso hipercromatismo nuclear e pleomorfismo celular. A proliferação de queratinócitos em padrão exofítico e a ausência de células invadindo camadas subjacentes da pele caracterizam as lesões obtidas como papilomas, as quais representam lesões pré-malignas que podem progredir a CEC. Tal resultado é compatível com o modelo de carcinogênese utilizado e apresenta-se como uma das vantagens do protocolo, uma vez que o desenvolvimento de CEC em humanos ocorre de maneira semelhante $[59,70]$.

\subsection{Caracterização bioquímica via Espectroscopia FTIR}

A espectroscopia ATR-FTIR foi utilizada para comparar as características bioquímicas apresentadas pelas lesões neoplásicas com a pele normal. A Figura 21 mostra o espectro médio obtido para cada grupo na região de $900-1800 \mathrm{~cm}^{-1}$ (região de impressão digital), a qual fornece informação de modos vibracionais associados a importantes componentes da célula.

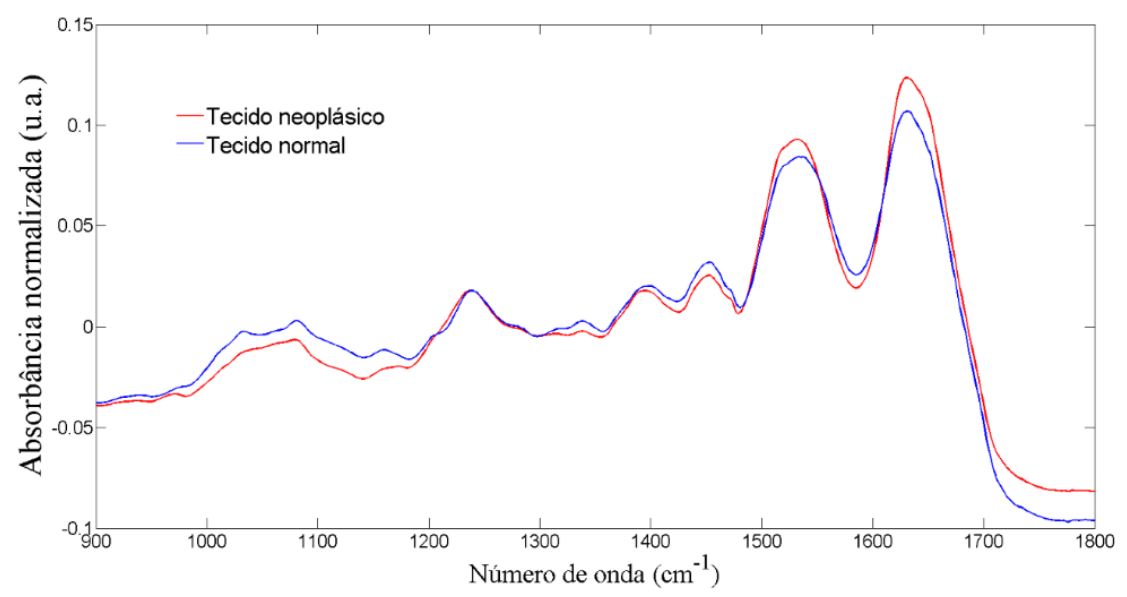

Figura 21. Espectro médio para tecido normal (linha azul) e tecido neoplásico (linha vermelha) 
Devido à sobreposição de bandas no espectro, calculou-se a derivada de segunda ordem da absorbância dos espectros obtidos para cada grupo, como mostrado na Figura 22.

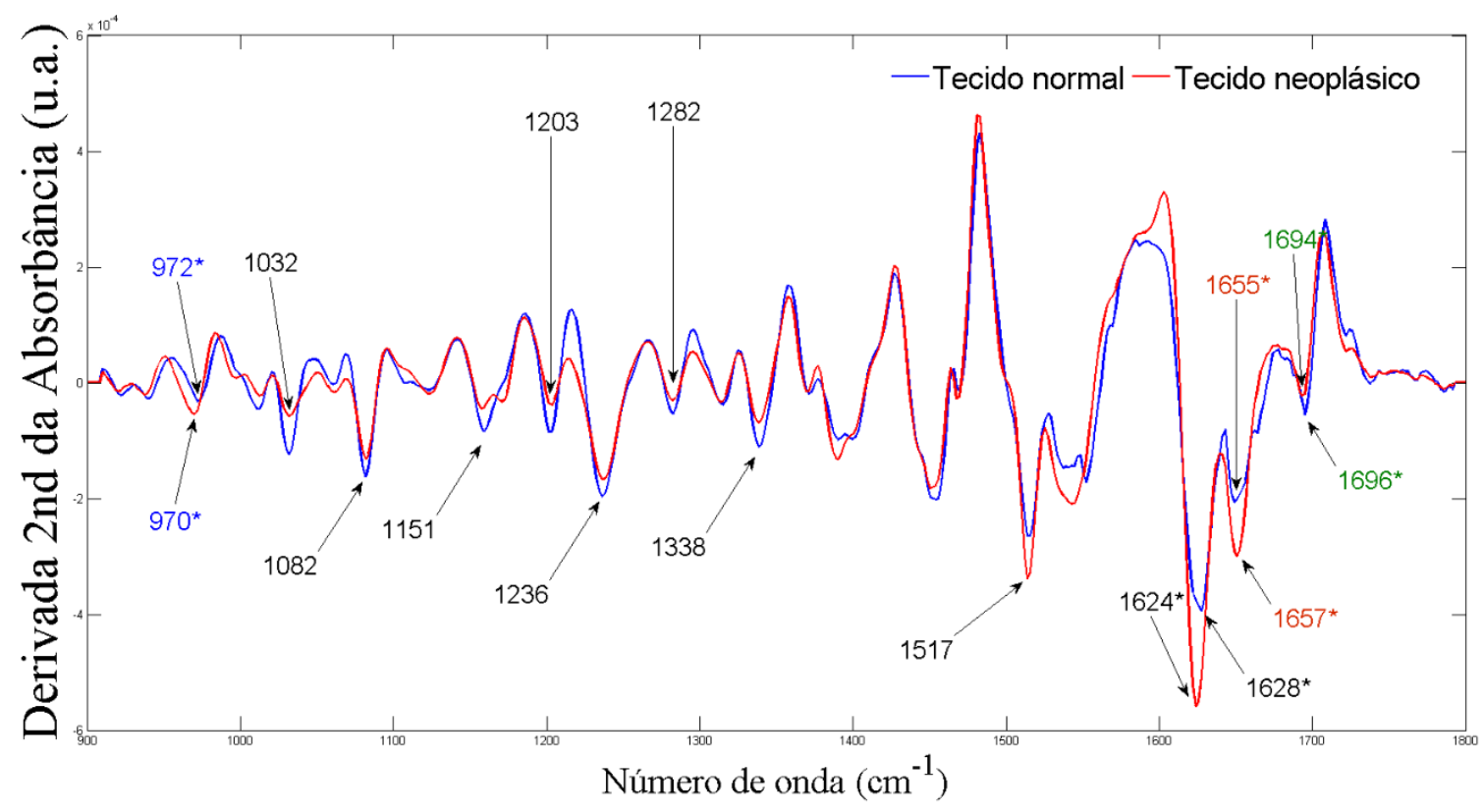

Figura 22. Média das derivadas de segunda ordem da absorbância de espectros provenientes de tecido normal e neoplásico

A Figura 22 mostra que ambos os grupos apresentaram modos vibracionais semelhantes, nos quais foi possível observar diferenças na intensidade de absorção e o deslocamento de picos em alguns casos. A coluna 1 da Tabela 2 mostra a posição observada para as bandas destacadas na Figura 22. Média das derivadas de segunda ordem da absorbância de espectros provenientes de tecido normal e neoplásico, enquanto a coluna 2 mostra a média obtida para a amplitude da derivada de segunda ordem de cada modo vibracional. O valor p obtido após o teste estatístico $t$-Student é mostrado na coluna 3 e a razão (Tumor/Normal) da amplitude da derivada para cada banda é mostrado na coluna 4. 
Tabela 2. Bandas de absorção observadas e valores p obtidos na comparação estatística das médias (teste $t$-Student)

\begin{tabular}{|c|c|c|c|c|c|}
\hline \multicolumn{2}{|c|}{1} & \multicolumn{2}{|c|}{2} & 3 & 4 \\
\hline \multicolumn{2}{|c|}{ Posição da banda } & \multicolumn{2}{|c|}{$\begin{array}{c}\text { Amplitude da derivada de segunda ordem da } \\
\text { banda (média } \pm \text { desvio padrão })\end{array}$} & p valor & Tumor/Normal \\
\hline Normal & Tumor & Normal & Neoplásico & & \\
\hline 972 & 970 & $-3,9 \times 10^{-5} \pm 3,8 \times 10^{-6}$ & $-5,8 \times 10^{-5} \pm 3,5 \times 10^{-6}$ & 0,0007 & 1,48 \\
\hline 1032 & 1032 & $-1,26 \times 10^{-4} \pm 6,8 \times 10^{-6}$ & $-6,7 \times 10^{-5} \pm 4,8 \times 10^{-6}$ & 0,0001 & 0,53 \\
\hline 1082 & 1082 & $-1,6 \times 10^{-4} \pm 6,4 \times 10^{-6}$ & $-1,3 \times 10^{-4} \pm 5,6 \times 10^{-6}$ & 0,0004 & 0,81 \\
\hline 1151 & 1151 & $-8,7 \times 10^{-5} \pm 2,1 \times 10^{-6}$ & $-4,8 \times 10^{-5} \pm 2,9 \times 10^{-6}$ & 0,0001 & 0,55 \\
\hline 1203 & 1203 & $-8,8 \times 10^{-5} \pm 6,1 \times 10^{-6}$ & $-4,6 \times 10^{-5} \pm 7,7 \times 10^{-6}$ & 0,0002 & 0,52 \\
\hline 1236 & 1236 & $-1,9 \times 10^{-4} \pm 6,0 \times 10^{-6}$ & $-1,6 \times 10^{-4} \pm 6,9 \times 10^{-6}$ & 0,0001 & 0,84 \\
\hline 1282 & 1282 & $-5,4 \times 10^{-5} \pm 2,7 \times 10^{-6}$ & $-3,1 \times 10^{-5} \pm 3,5 \times 10^{-6}$ & 0,0058 & 0,57 \\
\hline 1338 & 1338 & $-1,1 \times 10^{-4} \pm 4,1 \times 10^{-6}$ & $-6,8 \times 10^{-5} \pm 6,0 \times 10^{-6}$ & 0,0001 & 0,61 \\
\hline 1517 & 1517 & $-2,6 \times 10^{-4} \pm 5 \times 10^{-6}$ & $-3,4 \times 10^{-4} \pm 8,7 \times 10^{-6}$ & 0,0001 & 1,30 \\
\hline 1638 & 1634 & $-4,1 \times 10^{-4} \pm 9,9 \times 10^{-6}$ & $-5,6 \times 10^{-4} \pm 1,3 \times 10^{-5}$ & 0,0001 & 1,36 \\
\hline 1655 & 1657 & $-2,1 \times 10^{-4} \pm 5,3 \times 10^{-6}$ & $-3,0 \times 10^{-4} \pm 1,4 \times 10^{-5}$ & 0,0001 & 1,42 \\
\hline 1696 & 1694 & $-5,6 \times 10^{-5} \pm 2,5 \times 10^{-6}$ & $-2,4 \times 10^{-5} \pm 2,2 \times 10^{-6}$ & 0,0001 & 0,42 \\
\hline
\end{tabular}

A banda localizada em $972 \mathrm{~cm}^{-1}$ é atribuída ao estiramento simétrico das ligações monoéster de fosfato dianiônico em proteínas fosforiladas e vibrações dos grupos fosfato das ligações fosfodiéster no esqueleto de ácidos nucleicos [71,72]. Observa-se que a mesma sofre um deslocamento de $2 \mathrm{~cm}^{-1}$ e aumenta sua intensidade de absorção no tecido neoplásico, como apresentado na Figura 22 em azul. 
Bandas em 1200, 1236, 1280 e $1338 \mathrm{~cm}^{-1}$ são atribuídas a modos vibracionais de fibras colágenas $[71,73,74]$ e apresentaram-se menos intensos no tecido neoplásico comparado a pele normal. Contudo, a banda em $1236 \mathrm{~cm}^{-1}$ não é exclusiva de modos vibracionais de colágeno, uma vez que nesta mesma região há também absorção do estiramento assimétrico $\left(v_{\mathrm{as}} \mathrm{PO}_{2}^{-}\right)$de grupos fosfato das ligações fosfodiéster de ácidos nucleicos $[10,71,75]$.

A banda em $1080 \mathrm{~cm}^{-1}$ mostrou-se menos intensa no tecido neoplásico e resulta da soma de dois modos vibracionais: o estiramento simétrico de grupos fosfato $\left(v_{\mathrm{s}} \mathrm{PO}_{2}^{-}\right)$ $[10,71,75]$ de ácidos nucleicos e aos estiramentos C-O, C-C e movimentos de deformação do grupo C-O-H de moléculas de glicogênio [10,71]. Além destes, as bandas em 1032 e 1151 $\mathrm{cm}^{-1}$ também referem-se aos modos vibracionais de glicogênio [10,71], cuja absorção mostrou-se menos intensa no tecido neoplásico que na pele normal.

Analisando os valores apresentados na coluna 4 da tabela 2, observa-se que as razões obtidas para as bandas de glicogênio e colágeno apresentam valores similares e com pequenas flutuações em todos seus números de onda, exceto nas bandas onde há contribuição dos modos vibracionais de estiramento dos grupos fosfato (1082 e $\left.1236 \mathrm{~cm}^{-1}\right)$, como é representado graficamente na Figura 23.

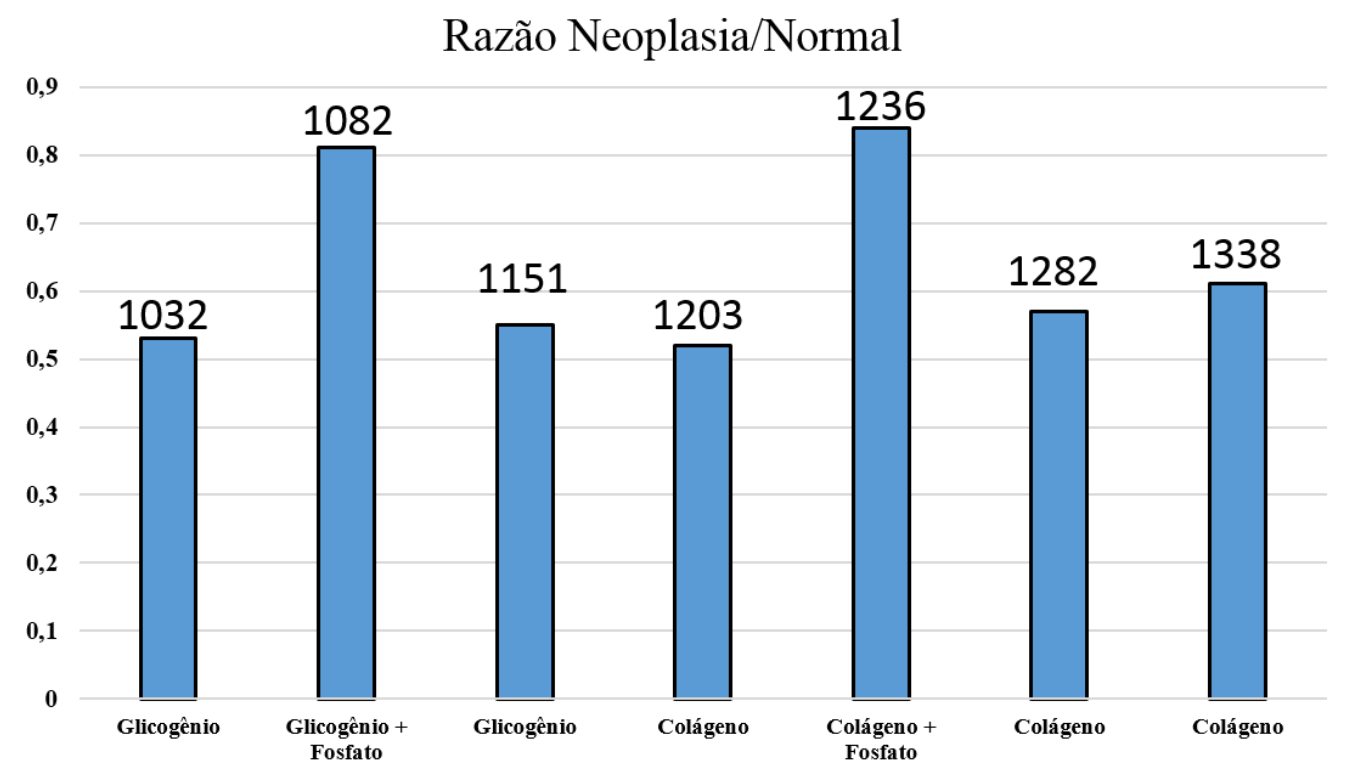

Figura 23. Valores obtidos para a razão da intensidade de absorção das bandas de tecido neoplásico por tecido normal 
As bandas localizadas na região $1500-1700 \mathrm{~cm}^{-1}$ fornecem informações sobre modos vibracionais provenientes de ligações peptídicas e estrutura secundária de proteínas [72]. A banda em $1517 \mathrm{~cm}^{-1}$, denominada em espectroscopia como amida II, resulta da combinação fora de fase da flexão de N-H no plano e estiramento $\mathrm{C}-\mathrm{N}$ com pequenas contribuições da flexão C-O no plano e estiramentos C-C e N-C de ligações peptídicas [71,72]. As bandas em 1638 [76], 1655 [71,76] e $1694 \mathrm{~cm}^{-1}$ [71,76] referem-se a amida I, a qual é caracterizada pelo estiramento $\mathrm{C}=\mathrm{O}$ com pequenas contribuições de estiramento $\mathrm{C}-\mathrm{N}$ fora de fase, deformação C-C-N e flexão de N-H no plano [72]. As bandas em 1638 e 1694 cm$^{-1}$ estão associadas a estrutura secundária folha- $\beta$ de proteínas, especificamente a configuração paralela e antiparalela, respectivamente. Como mostrado na Figura 22, a banda atribuída a configuração paralela possui maior intensidade de absorção no tecido neoplásico e deslocou-se para um número de onda menor (asterisco preto), ao passo que a folha $\beta$ antiparalela deslocou-se $2 \mathrm{~cm}^{-1}$ para um maior número de onda (asterisco verde) e apresentou-se menos intensa no tecido neoplásico. Por fim, a banda em $1655 \mathrm{~cm}^{-1}$ está associada às vibrações da estrutura $\alpha$ hélice de proteínas e mostrou-se mais intensa no tecido neoplásico e deslocamento de $2 \mathrm{~cm}^{-1}$ em direção a números de onda superiores (asterisco vermelho).

\subsection{Análise de agrupamento}

A partir dos espectros coletados para cada grupo experimental, avaliou-se o grau de similaridade entre os mesmos através da técnica de análise hierárquica por agrupamento (Hierarquical Cluster Analysis, HCA). Visando encontrar o melhor parâmetro para a classificação dos espectros, aplicou-se a técnica de HCA a todos os espectros coletados e também aos espectros médio obtidos para cada corte histológico. Para isto obteve-se a matriz de similaridade usando dois tipos de distância estatística (euclidiana e coeficiente de correlação), seguido de agrupamento via método de ligação de Ward.

O gráfico obtido na análise de agrupamento é dado na forma de "árvore" (dendograma), o qual permite analisar a maneira que os espectros se distribuem de acordo com sua semelhança, possibilitando organizar hierarquicamente os dados e classifica-los em um número de grupos pré-definidos. 
Usando-se o coeficiente de correlação como distância estatística obteve-se o dendograma mostrado na Figura 24, o qual classifica a derivada de segunda ordem da absorbância obtida para todos os espectros coletados, sendo 70 espectros provenientes de 13 lâminas com pele normal e 70 espectros obtidos de 13 lâminas com tecido neoplásico.

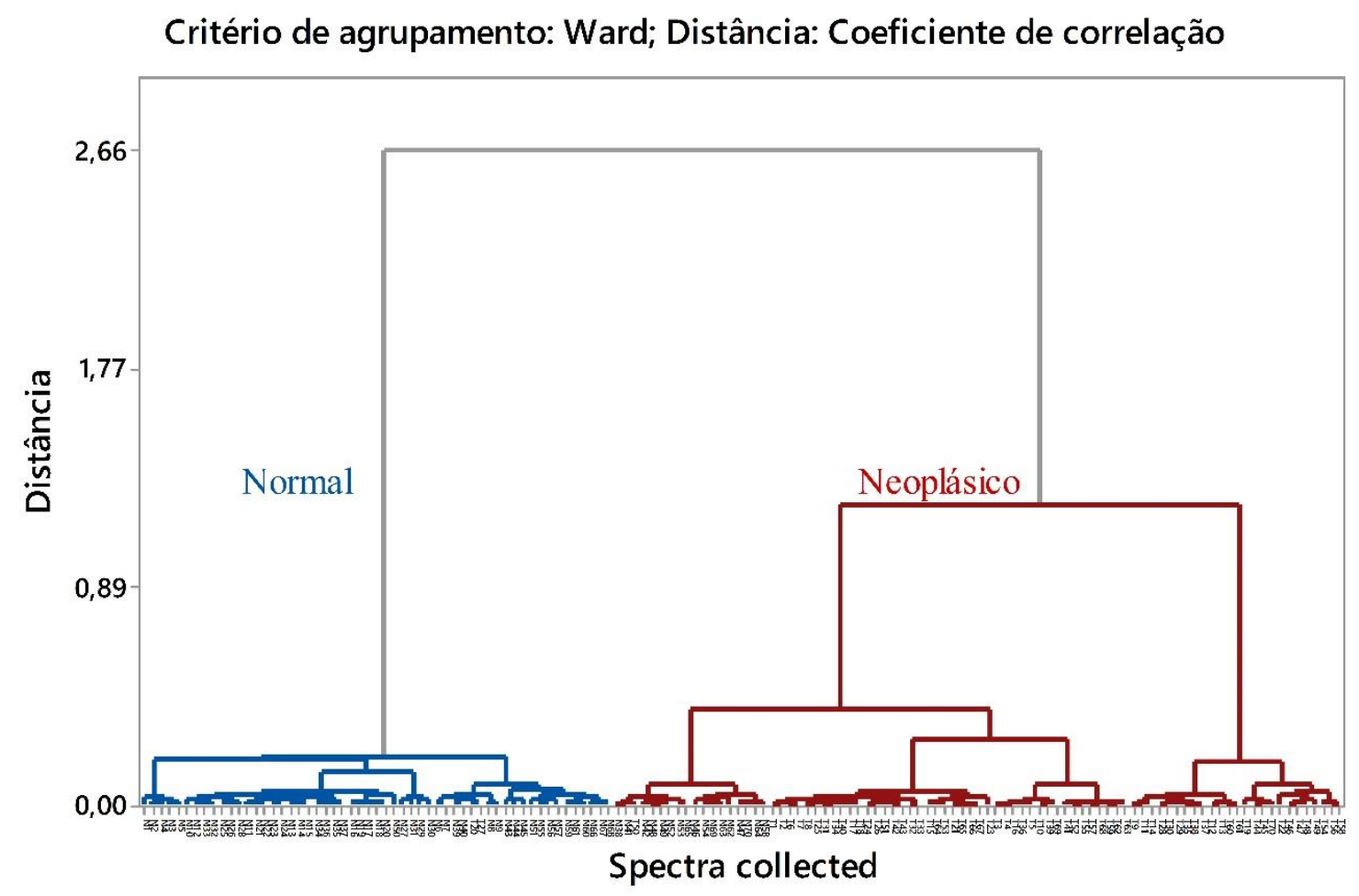

Figura 24. Classificação dos espectros de tecido normal e neoplásico em função do nível de similaridade para todos os espectros obtidos.

Os espectros identificados como N1-N70 correspondem aos 70 espectros coletados de lâminas com pele normal e T1-T70 representam os espectros provenientes de tecido neoplásico. Os grupos obtidos são mostrados nas cores azul e vermelho. Observa-se que os espectros organizados no grupo azul são majoritariamente de tecido normal, enquanto o grupo vermelho é formado por espectros de tecido neoplásico. $\mathrm{O}$ eixo $\mathrm{Y}$ do dendograma informa o grau de semelhança que os dados pertencentes a cada grupo possuem entre si.

Considerando a maneira que os espectros foram distribuídos nos grupos mostrados no dendograma, calculou-se a acurácia, sensibilidade e especificidade do método utilizando a distância euclidiana e coeficiente de correlação, como mostra a Tabela 3. 
Tabela 3. Distribuição dos dados para cálculo da acurácia obtida com a análise por agrupamento via distância euclidiana e coeficiente de correlação considerando-se todos os espectros obtidos

\begin{tabular}{|c|c|c|c|c|c|c|c|}
\hline \multicolumn{8}{|c|}{ Critério de agrupamento: Ward; Distância: Coeficiente de correlação; Dados: Todos os espectros coletados } \\
\hline & $\begin{array}{c}\text { Verdadeiro } \\
\text { positivo } \\
\text { (VP) }\end{array}$ & $\begin{array}{c}\text { Verdadeiro } \\
\text { negativo } \\
\text { (VN) }\end{array}$ & $\begin{array}{c}\text { Falso } \\
\text { positivo } \\
\text { (FP) }\end{array}$ & $\begin{array}{c}\text { Falso } \\
\text { negativo } \\
\text { (FN) }\end{array}$ & $\begin{array}{c}\text { Acurácia } \\
(\%)\end{array}$ & $\begin{array}{c}\text { Sensibilidade } \\
(\%)\end{array}$ & $\begin{array}{c}\text { Especificidade } \\
(\%)\end{array}$ \\
\hline Espectros & 68 & 53 & 17 & 2 & 86,4 & 97.1 & 75.7 \\
\hline
\end{tabular}

Considerou-se como verdadeiro positivo (VP) os espectros de tecido neoplásico no grupo neoplásico; verdadeiro negativo ( $\mathrm{VN}$ ) os espectros de tecido normal no grupo normal; falso positivo (FP) os espectros de tecido normal no grupo neoplásico e falso negativo (FN) os espectros de tecido neoplásico no grupo normal. A acurácia, sensibilidade e especificidade são medidas estatísticas do desempenho de um teste de classificação binária. A sensibilidade mede a habilidade do método em identificar corretamente uma proposição, enquanto a especificidade mede a capacidade da técnica em excluir corretamente uma proposição.

Seguindo o mesmo procedimento descrito anteriormente, aplicou-se a análise por agrupamento nos espectros médio obtido para cada corte histológico. Sendo assim, os espectros identificados como N1-N13 na Figura 25 correspondem a derivada de segunda ordem do espectro médio obtido para cada corte histológico de pele normal, e T1-T13 referese às 13 lâminas com tecido neoplásico. 


\section{Critério de agrupamento: Ward; Distância: Coeficiente de correlação}

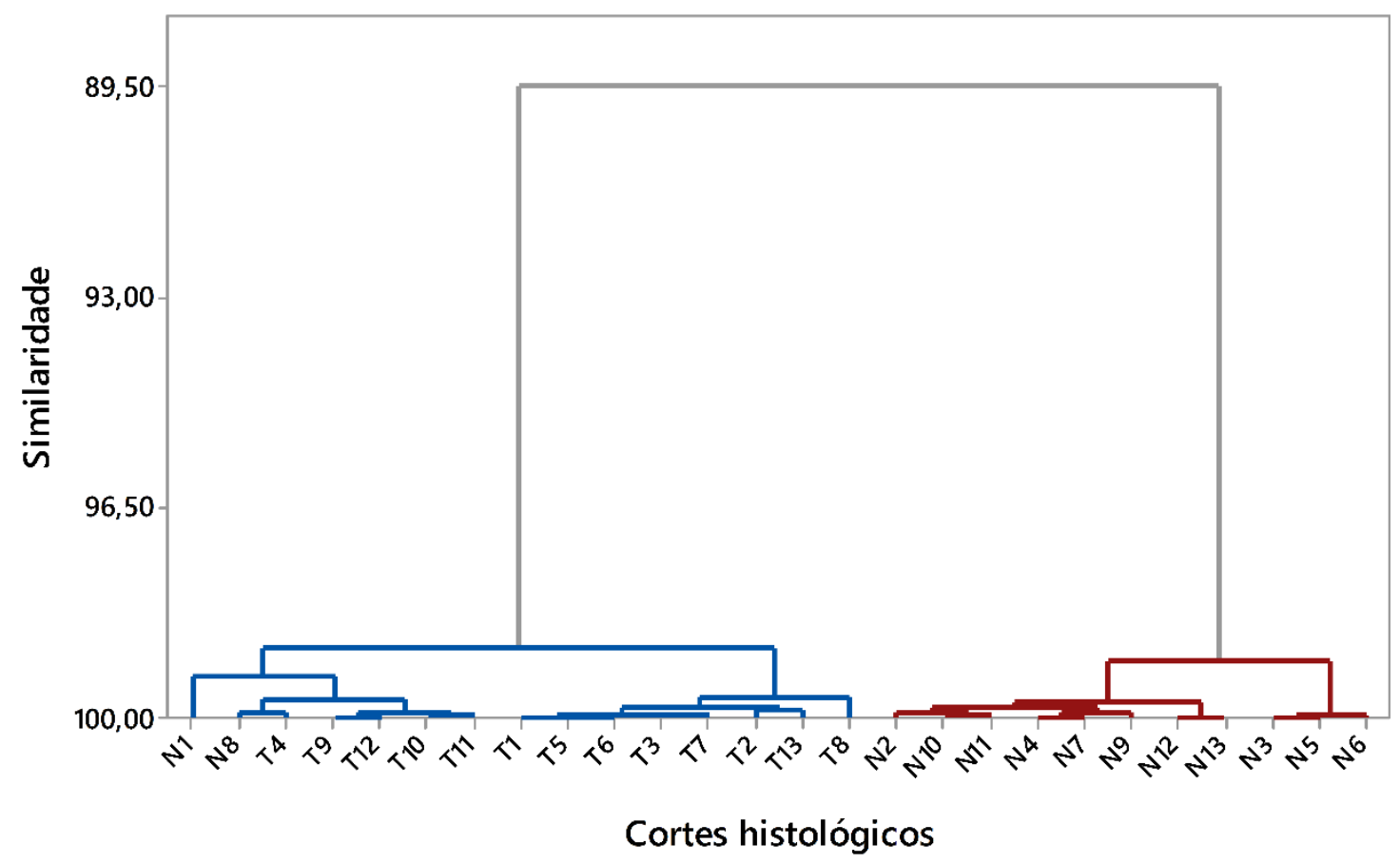

Figura 25. Classificação dos espectros de tecido normal e neoplásico em função do nível de similaridade para o espectro médio por corte histológico.

A partir da distribuição dos dados na Figura 25, obteve-se a Tabela 4.

Tabela 4. Distribuição dos dados para cálculo da acurácia obtida com a análise por agrupamento via distância euclidiana e coeficiente de correlação considerando-se o espectro médio por corte histológico

Critério de agrupamento: Ward; Distância: Coeficiente de correlação; Dados: Espectro médio obtido por corte histológico

\begin{tabular}{|c|c|c|c|c|c|c|c|}
\hline \multicolumn{8}{|c|}{ histológico } \\
\hline & $\begin{array}{c}\text { Verdadeiro } \\
\text { positivo } \\
\text { (VP) }\end{array}$ & $\begin{array}{c}\text { Verdadeiro } \\
\text { negativo } \\
\text { (VN) }\end{array}$ & $\begin{array}{c}\text { Falso } \\
\text { positivo } \\
(\text { FP) }\end{array}$ & $\begin{array}{c}\text { Falso } \\
\text { negativo } \\
\text { (FN) }\end{array}$ & $\begin{array}{c}\text { Acurácia } \\
(\%)\end{array}$ & $\begin{array}{c}\text { Sensibilidade } \\
(\%)\end{array}$ & $\begin{array}{c}\text { Especificidade } \\
(\%)\end{array}$ \\
\hline Espectros & 13 & 11 & 2 & 0 & 92,3 & 100 & 84,6 \\
\hline
\end{tabular}




\section{Discussão}

Como descrito anteriormente, a região de impressão digital (900-1800 cm $\left.\mathrm{cm}^{-1}\right)$ fornece informações de modos vibracionais associados a importantes componentes da célula. No entanto, caracterizar a dinâmica bioquímica de uma amostra biológica é muito mais complexo que a simples identificação e descrição de determinado componente a partir de seus modos vibracionais. Em um sistema biológico, o efeito de cada estrutura pode interagir com modos vibracionais absorvedores na mesma região e resultar na amplificação ou redução de determinada banda. Além disso, o metabolismo de uma célula neoplásica não é totalmente compreendido, e até o momento sabe-se que as características bioquímicas observadas variam de acordo com o tipo de célula e estadiamento da doença [77].

A redução na amplitude da derivada de segunda ordem dos modos vibracionais associados a colágeno indica que tal estrutura apresenta-se em menor quantidade no tecido neoplásico que no tecido normal. Mantsch e colaboradores generalizaram tal comportamento como característico de carcinomas potencialmente malignos [74], que de fato se enquadra às lesões abordadas neste trabalho, uma vez que foi observado pela análise histopatológica um grau moderado de displasia celular. A redução de bandas associadas ao colágeno foi também observada durante a avaliação espectroscópica das alterações bioquímicas em pele normal causadas por carcinoma basocelular [78], a qual foi justificada como consequência da degradação das fibras colágenas que compõem a matriz extracelular. De fato, trabalhos na literatura mostram que certas células tumorais, incluindo células de CEC, liberam enzimas específicas que degradam as fibras de colágeno para que o tumor possa se espalhar pelo tecido circundante e metastizar para locais distantes $[79,80]$.

Em termos energéticos, o metabolismo acelerado e a proliferação descontrolada de células neoplásicas demandam maior gasto energético que células normais. A principal fonte de energia de toda célula do nosso organismo provém da degradação de moléculas de glicose, a qual é naturalmente armazenada na célula na forma de glicogênio [2]. Como descrito na seção anterior, o glicogênio possui modos vibracionais ativos na região de impressão digital (1032, 1082 e $\left.1151 \mathrm{~cm}^{-1}\right)$, os quais apresentaram-se menos intensos no tecido neoplásico que na pele normal, sugerindo uma redução no conteúdo energético da célula que é condizente 
com a intensa atividade metabólica e demanda de energia das células modificadas em proliferação.

Como mostrado na Figura 23, as razões obtidas pelas bandas de colágeno e glicogênio apresentam valores semelhantes, exceto nas bandas onde há contribuição de modos vibracionais de estiramento de grupos fosfato, o que nos permite concluir que as bandas de fosfato em 1080 e $1236 \mathrm{~cm}^{-1}$ aumentam no tecido neoplásico, porém, a absorção apresentada pelas mesmas sofre influência de outras componentes celulares que estão reduzidas no tecido neoplásico (colágeno e glicogênio). $\mathrm{O}$ aumento na intensidade de absorção das bandas em 1080 e $1236 \mathrm{~cm}^{-1}$ implica um aumento no conteúdo de ácidos nucleicos e representa uma das mais importantes e particulares características apresentadas pelas células neoplásicas: as inúmeras e incontroláveis replicações do DNA modificado [77].

A proliferação descontrolada, o aumento da divisão celular, a imortalização e outras características anormais apresentadas pela célula cancerosa violam as regras mais básicas de comportamento, pelas quais os organismos multicelulares são construídos e mantidos. Tais características decorrem de falhas no sistema de reparo do DNA, ciclo celular e morte programada da célula, os quais são regulados por um complexo sistema de comunicação, governado por proteínas especializadas em constantes processos de ativação e desativação [2], os quais incluem a fosforilação de proteínas como principal mecanismo. Neste contexto, o aumento na intensidade da banda em $970 \mathrm{~cm}^{-1}$ indica um aumento na expressão de proteínas fosforiladas no tecido neoplásico, o qual somado aos resultados obtidos para as bandas de amida I e II indicam superexpressão proteica no tecido neoplásico, que pode ser explicada pela intensa atividade metabólica das células neoplásicas e sua demanda por proteínas sinalizadoras. Os deslocamentos observados na posição das bandas referentes as estruturas $\alpha$-hélice $\left(1655 \mathrm{~cm}^{-1}\right)$ e folha- $\beta$ paralela $\left(1638 \mathrm{~cm}^{-1}\right)$ da amida I indicam alterações nas pontes de hidrogénio entre os grupos de peptídeos que caracterizam a geometria de tais estruturas, o que pode induzir danos no enovelamento de proteínas e resultar em perda definitiva da função biológica ou mutação [72].

Comparando-se os resultados mostrados nas Tabelas 3 e 4, observou-se que a análise por agrupamento foi mais eficaz considerando-se o espectro médio por corte histológico, no qual foi observado $92,3 \%$ de acurácia, $100 \%$ de sensibilidade e 84,6\% de especificidade. 


\section{Conclusões}

O presente estudo conclui que a análise de agrupamento mostrou de precisão satisfatória na discriminação de espectros provenientes de lesões neoplásicas e tecido sadio, os quais apresentaram sobretudo diferenças nos números de onda associados ao conteúdo de ácidos nucleicos, colágeno, proteínas e açúcares. Neste sentido, a espectroscopia ATR-FTIR mostrou ser uma ferramenta útil para complementar a análise histopatológica na rotina clínica para o diagnóstico da CEC. 


\section{Referências Bibliográficas}

355

[1] COOPER, G. Elements of Human Cancer. Segunda ed. Jones \& Bartlett, 2006. p.

[2] ALBERTS, B. et al. Biologia Molecular da Célula. Artmed, 2010. p. 1728

[3] Instituto Nacional do Câncer (INCA). Disponível em: <http://www2.inca.gov.br/wps/wcm/connect/cancer/site/oquee>. Acesso em: 28 fev. 2015.

[4] BOYLE, P. e LEVIN, B. World Cancer Report 2008. Disponível em: <http://www.iarc.fr/en/publications/pdfs-online/wcr/2008/>. Acesso em: 25 abr. 2014.

[5] INCA. Estimativas de câncer no Brasil para 2014. Disponível em: <http://www.inca.gov.br/estimativa/2014/estimativa-24042014.pdf>. Acesso em: 26 fev. 2014.

[6] WERNER, B. Biópsia de pele e seu estudo histológico . Por quê ? Para quê ? Anais Brasileiros de Dermatologia, v. 84, n. 4, p. 391-395, 2009.

[7] DIEM, M. et al. Molecular pathology via IR and Raman spectral imaging. Journal of biophotonics, v. 6, p. 855-86, 2013.

[8] KRAFFT, C. e SERGO, V. Biomedical applications of Raman and infrared spectroscopy to diagnose tissues. Spectroscopy, v. 20, n. 5-6, p. 195-218, 2006.

[9] DIEM, M. et al. Applications of Infrared and Raman Microspectroscopy of Cells and Tissue in Medical Diagnostics: Present Status and Future Promises. Spectroscopy: An International Journal, v. 27, n. 5, p. 463-496, 2012.

[10] DIEM, M.;; GRIFFITHS, P. e CHALMERS, J. Vibrational Spectroscopy for Medical Diagnosis. Wiley, 2008. p. 358

[11] PETRICH, W. Mid-Infrared and Raman spectroscopy for medical diagnostics. Applied Spectroscopy Reviews, v. 36, p. 181-237, 2001.

[12] NAUMANN, D. FT-Infrared and FT-Raman spectroscopy in biomedical research. Applied Spectroscopy Reviews, v. 36, p. 239-298, 2001. 2015.

[13] BYRNE, H. J. et al. Spectropathology for the next generation: Quo vadis? Analyst,

[14] DUBAS, L. E. e INGRAFFEA, A. Nonmelanoma skin cancer. Facial plastic surgery clinics of North America, v. 21, p. 43-53, 2013. 
[15] KIM, R. H. e ARMSTRONG, A. W. Nonmelanoma skin cancer. Dermatologic clinics, v. 30, p. 125-39, 2012.

[16] LEE, D. a e MILLER, S. J. Nonmelanoma skin cancer. Facial plastic surgery clinics of North America, v. 17, p. 309-24, 2009.

[17] BICKERS, D. R. e ATHAR, M. Oxidative stress in the pathogenesis of skin disease. The Journal of investigative dermatology, v. 126, p. 2565-75, 2006.

[18] BONERANDI, J. J. et al. Guidelines for the diagnosis and treatment of cutaneous squamous cell carcinoma and precursor lesions. Journal of the European Academy of Dermatology and Venereology, v. 25, p. 1-51, 2011.

[19] BRODERS, A. C. Squamous-cell epithelioma of the skin. Annals of Surgery, v. LXXIII, p. 141-160, 1921.

[20] WILSON, J. a. e EVANS, A. T. Pathology of malignant tumours of the skin. Surgery (Oxford), v. 28, p. 473-477, 2010.

[21] BROUGHAM, N. D. L. S. et al. The incidence of metastasis from cutaneous squamous cell carcinoma and the impact of its risk factors. Journal of surgical oncology, v. 106, p. 811-5, 2012.

[22] STUART, B. Infrared Spectroscopy: Fundamentals and applications: John Wiley \& Sons, 2004. p. 208

[23] SKOOG, D. A.;; CROUCH, S. R. e HOLLER, J. Principles of Instrumental Analysis: Brooks/Cole, 2006. p. 1056

[24] Espectro Eletromagnético. Disponível em: <http://universoracionalista.org/redshift-e-efeito-doppler/>. Acesso em: 2 mar. 2015.

[25] SALA, O. Fundamentos da espectroscopia Raman e no Infravermelho. 2nd. ed. São Paulo: Editora Unesp, 2008. p. 276

[26] BENETTI, C. Estudo da reparação óssea por espectroscopia ATR-FTIR após remoção de fragmento da região mandibular com laser de Er,Cr:YSGG ou broca multilaminada. Universidade de São Paulo, 2014.

[27] DORLING, K. M. e BAKER, M. J. Highlighting attenuated total reflection Fourier transform infrared spectroscopy for rapid serum analysis. Trends in biotechnology, v. 31, p. 327-8, 2013.

[28] BAKER, M. J. et al. Using Fourier transform IR spectroscopy to analyze biological materials. Nature protocols, v. 9, p. 1771-91, 2014. 
[29] CIURCZAK, E. Infrared sample preparation techniques. Spectroscopy, v. 9, p. 18-19, 1994.

[30] BASSAN, P. et al. Resonant Mie scattering (RMieS) correction of infrared spectra from highly scattering biological samples. Analyst, v. 135, p. 268-77, 2010.

[31] CHAN, K. L. A. e KAZARIAN, S. G. Correcting the effect of refraction and dispersion of light in FT-IR spectroscopic imaging in transmission through thick Infrared windows. Analytical Chemistry, v. 85, p. 1029-1036, 2013.

[32] KING, S. W. e MILOSEVIC, M. A method to extract absorption coefficient of thin films from transmission spectra of the films on thick substrates. Journal of Applied Physics, v. 111, p. 073109, 2012.

[33] BASSAN, P. et al. FTIR microscopy of biological cells and tissue: data analysis using resonant Mie scattering (RMieS) EMSC algorithm. Analyst, v. 137, p. 1370-7, 2012.

[34] SEVERCAN, F. e HARIS, P. Vibrational Spectroscopy in Diagnosis and Screening: IOS Press, 2012. p. 432

[35] FILIK, J. et al. Electric field standing wave artefacts in FTIR micro-spectroscopy of biological materials. Analyst, v. 137, p. 853-61, 2012.

[36] GREENLER, R. G. Infrared study of adsorbed molecules on metal surfaces by reflection techniques. The Journal of Chemical Physics, v. 44, p. 310, 1966.

[37] WROBEL, T. P. et al. Electric field standing wave effects in FT-IR transflection spectra of biological tissue sections: Simulated models of experimental variability. Vibrational Spectroscopy, v. 69, p. 84-92, 2013.

[38] SEARCH, H. et al. Optical standing-wave artifacts in reflection-absorption FTIR microspectroscopy of biological materials. Journal of Physics: Conference Series, v. 359, p. 012006, 2012.

[39] KAZARIAN, S. G. e CHAN, K. L. A. ATR-FTIR spectroscopic imaging: recent advances and applications to biological systems. Analyst, v. 138, p. 1940-51, 2013.

[40] AFANASYEVA, N. I. et al. Diagnostics of cancer by fiber optic evanescent wave FTIR (FEW-FTIR) spectroscopy. SPIE proceedings, p. 154-157, 1996.

[41] SUKUTA, S. e BRUCH, R. Factor Analysis of Cancer Fourier Transform Infrared Evanescent Wave Fiberoptical ( FTIR-FEW ) Spectra. Lasers in Surgery and Medicine, v. 24, p. 382-388, 1999.

[42] SILVA DE CARVALHO, L. F. Análise de processos inflamatórios por espectroscopia vibracional em altos números de onda. Universidade Federal do ABC. 2012. 
[43] DONG, L. et al. Evaluation of FTIR spectroscopy as diagnostic tool for colorectal cancer using spectral analysis. Spectrochimica acta. Part A, Molecular and biomolecular spectroscopy, v. 122, p. 288-94, 2014.

[44] RIGAS, B. et al. Human colorectal cancers display abnormal Fourier-transform infrared spectra. Proceedings of the National Academy of Sciences of the United States of America, v. 87, p. 8140-8144, 1990.

[45] WANG, J. et al. FT-IR spectroscopic analysis of normal and cancerous tissues of esophagus. World J Gastroenterol, v. 9, p. 1897-1899, 2003.

[46] BIRD, B. et al. Infrared spectral histopathology (SHP): a novel diagnostic tool for the accurate classification of lung cancer. Laboratory investigation; a journal of technical methods and pathology, v. 92, p. 1358-73, 2012.

[47] SUN, X. et al. Detection of lung cancer tissue by attenuated total reflection-Fourier transform infrared spectroscopy-a pilot study of 60 samples. The Journal of surgical research, v. 179, p. 33-8, 2013.

[48] GAO, T.; FENG, J. e CI, Y. Human Breast carcinomal tissues display distinctive FTIR spectra: Implication for the histological characterization of carcinomas. Analytical Cellular Pathology, v. 18, p. 87-93, 1999.

[49] LY, E. et al. Histopathological characterization of primary cutaneous melanoma using infrared microimaging: a proof-of-concept study. The British journal of dermatology, v. 162, p. 1316-23, 2010.

[50] WOOD, B. R. et al. An investigation into FTIR spectroscopy as a biodiagnostic tool for cervical cancer. Biospectroscopy, v. 2, p. 143-153, 1998.

[51] PEREIRA, T. M. et al. The characterization of normal thyroid tissue by microFTIR spectroscopy. Analyst, v. 138, p. 7094-100, 2013.

[52] BAKER, M. J. et al. Investigating FTIR based histopathology for the diagnosis of prostate cancer. Journal of biophotonics, v. 2, p. 104-13, 2009.

[53] FERNANDEZ, D. C. et al. Infrared spectroscopic imaging for histopathologic recognition. Nature biotechnology, v. 23, p. 469-74, 2005.

[54] LEHNINGER, A. Princípios de Bioquímica. Sarvier, 2002. p. 718

[55] $O$ que são as proteinas? Disponível em: <http://www.explicatorium.com/quimica/Proteinas.php>. Acesso em: 9 mar. 2015.

[56] BOND, T. P.; DOMAINS, B. e DOMAINS, C. From Sequence to Structure. 
[57] Lipídios e triglicerídios. Disponível em: <http://wikiciencias.casadasciencias.org/index.php/Triglicer\%C3\%ADdeos〉. Acesso em: 25 abr. 2014.

[58] GOULART, V. et al. Noninvasive monitoring of photodynamic therapy on skin neoplastic lesions using the optical attenuation coefficient measured by optical coherence tomography. Journal of Biomedical Optics, v. 20, n. 5, p. 051007-1, 2015.

[59] ABEL, E. et al. Multi-stage chemical carcinogenesis in mouse skin: Fundamentals and applications. Nature protocols, v. 9, p. 1350-1362, 2009.

[60] JUNQUEIRA, L. C. e CARNEIRO, J. Histologia Basica. [S.1.]: GUANABARA KOOGAN S/A, 2011. p. 520

[61] SEBISKVERADZE, D. et al. Effects of digital dewaxing methods on K-meansclusterized IR images collected on formalin-fixed paraffin-embedded samples of skin carcinoma. IEEE proceedings, p. 1-6, 2008.

[62] TFAYLI, A. et al. Digital dewaxing of Raman signals: discrimination between nevi and melanoma spectra obtained from paraffin-embedded skin biopsies. Applied spectroscopy, v. 63, p. 564-70, 2009.

[63] HUGHES, C. et al. Assessment of paraffin removal from prostate FFPE sections using transmission mode FTIR-FPA imaging. Analytical Methods, v. 6, p. 1028-1035, 2014.

[64] Ó FAOLÁIN, E. et al. A study examining the effects of tissue processing on human tissue sections using vibrational spectroscopy. Vibrational Spectroscopy, v. 38, p. $121-127,2005$.

[65] MIAN, S. a. et al. Development of a dewaxing protocol for tissue-engineered models of the oral mucosa used for Raman spectroscopic analysis. Applied Spectroscopy Reviews, v. 49, p. 614-617, 2014.

[66] KANDYALA, R.;; RAGHAVENDRA, S. P. C. e RAJASEKHARAN, S. T. Xylene: An overview of its health hazards and preventive measures. Journal of oral and maxillofacial pathology, v. 14, p. 1-5, 2010.

[67] WARTEWIG, S. IR and Raman Spectroscopy: Fundamental processing: Wiley, 2003. p. 173

[68] KOZICKI, M. et al. Spectroscopic investigation into the effects of chloroquine on Plasmodium falciparum - infected red blood cells. Analyst, 2015.

[69] HÄRDLE, W. e SIMAR, L. Applied multivariate statistical analysis. 2nd. ed.: Springer, 2007. p. 455 
[70] SILVA, A. P. Avaliação histopatológica do tratamento de carcinoma espinocelular cutâneo em camundongos usando terapia fotodinâmica mediada por azul de metileno. Universidade de São Paulo, 2014.

[71] MOVASAGHI, Z.;; REHMAN, S. e UR REHMAN, D. I. Fourier Transform Infrared (FTIR) spectroscopy of biological tissues. Applied Spectroscopy Reviews, v. 43, p. 134-179, 2008.

[72] BARTH, A. Infrared spectroscopy of proteins. Biochimica et biophysica acta, v. 1767, p. 1073-101, 2007.

[73] BELBACHIR, K. et al. Collagen types analysis and differentiation by FTIR spectroscopy. Analytical and bioanalytical chemistry, v. 395, p. 829-37, 2009.

[74] JACKSON, M. et al. Beware of connective tissue proteins : assignment and implications of collagen absorptions in infrared spectra of human tissues. Biochimica et Biophysica Acta (BBA), v. 1, p. 1-6, 1995.

[75] CULL, K. B. et al. Phosphodiester Stretching Bands in the Infrared Spectra of Human Tissues and Cultured Cells. Applied Spectroscopy, v. 45, p. 1563-1567, 1991.

[76] KHURANA, R. e FINK, A. L. Do parallel alpha-helix proteins have a unique Fourier transform infrared spectrum? Biophysical Journal, v. 78, p. 994-1000, 2000.

[77] SIMONOVA, D. e KARAMANCHEVA, I. Application of Fourier Transform Infrared Spectroscopy for Tumor Diagnosis. Biotechnology \& Biotechnological Equipment, v. 27, p. 4200-4207, 2014.

[78] BODANESE, B. et al. Discrimination of basal cell carcinoma and melanoma from normal skin biopsies in vitro through Raman spectroscopy and principal component analysis. Photomedicine and Laser Surgery, v. 30, p. 381-7, 2012.

[79] FUNDYLER, O.;; KHANNA, M. e SMOLLER, B. R. Metalloproteinase-2 expression correlates with aggressiveness of cutaneous squamous cell carcinomas. Modern pathology: an official journal of the United States and Canadian Academy of Pathology, v. 17, p. 496-502, 2004.

[80] MARTINS, V. L. et al. Increased invasive behaviour in cutaneous squamous cell carcinoma with loss of basement-membrane type VII collagen. Journal of Cell Science, v. 122, p. 1788-99, 2009. 


\section{Anexos}

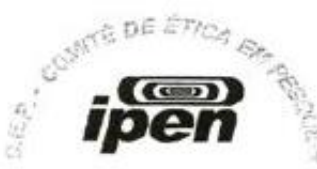

Parecer - Projeto $N^{\circ} \mathbf{7 1 / 1 0}$ - CEUA-IPEN/SP

Com base nos pareceres apresentados pelos relatores, o protocolo de pesquisa “ESPECTROSCOPIA DE FLUORESCENCIA NA MONITORAÇĀO E OTIMIZAÇÃO DA TERAPIA FOTODINÂMICA DE CARCINOMA ESPINOCELULAR IN VIVO" de responsabilidade do pesquisador DENISE MARIA ZEZELL foi considerado APROVADO.

Tendo om vista a legislaçăo vigente, devem ser encaminhados, a este Comitê, relatórios anuais (parciais ou finais, dependendo da duraçăo do projeto) referentes ao andamento da pesquisa. Após o término da pesquisa, uma cópia do trabalho deve ser encaminhada a este CEUA.

Săo Paulo, 21 de dezembro de 2010

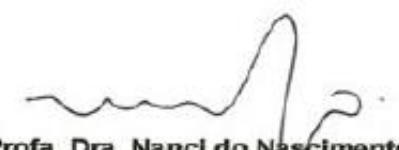

Profa. Dra. Nanci do Nascimento Coordenadora do CEUA-IPEN

COMITE DE ÉTICA EM PESQUISA ANIMAL

Av Prof Lineu Prestes, 2242 - Cidede Universitaria - CEP O55CO-D00 - Săo Paujo - SP Tolefone: (011) 3133-9698 - Fax (011) 3133-9709 
Article

\title{
ATR-FTIR Spectroscopy for the Assessment of Biochemical Changes in Skin Due to Cutaneous Squamous Cell Carcinoma
}

\author{
Cássio A. Lima ${ }^{1}$, Viviane P. Goulart ${ }^{1}$, Luciana Côrrea ${ }^{2}$, Thiago M. Pereira ${ }^{1,3}$ and \\ Denise M. Zezell ${ }^{1, *}$
}

1 Center for Lasers and Applications, Instituto de Pesquisas Energéticas e Nucleares, IPEN-CNEN/SP, São Paulo SP 05508-000, Brazil; E-Mails: cassiolima@usp.br (C.A.L.); vi.pgoulart@gmail.com (V.P.G.); thiagomartinipereira@gmail.com (T.M.P.)

2 School of Dentistry, Universidade de São Paulo, São Paulo SP 05508-000, Brazil; E-Mail: 1correa@usp.br

3 Instituto de Ciência e Tecnologia (ICT), Universidade Federal de São Paulo, São José dos Campos SP 12.231-280, Brazil

* Author to whom correspondence should be addressed; E-Mail: zezell@usp.br; Tel.: +55-11-3133-9370; Fax: +55-11-3133-9374.

Academic Editor: Herbert Schneckenburger

Received: 15 December 2014 / Accepted: 13 March 2015 / Published: 24 March 2015

\begin{abstract}
Nonmelanoma skin cancers represent 95\% of cutaneous neoplasms. Among them, squamous cell carcinoma (SCC) is the more aggressive form and shows a pattern of possible metastatic profile. In this work, we used Fourier transform infrared spectroscopy (FTIR) spectroscopy to assess the biochemical changes in normal skin caused by squamous cell carcinoma induced by multi-stage chemical carcinogenesis in mice. Changes in the absorption intensities and shifts were observed in the vibrational modes associated to proteins, indicating changes in secondary conformation in the neoplastic tissue. Hierarchical cluster analysis was performed to evaluate the potential of the technique to differentiate the spectra of neoplastic and normal skin tissue, so that the accuracy obtained for this classification was $86.4 \%$. In this sense, attenuated total reflection (ATR)-FTIR spectroscopy provides a useful tool to complement histopathological analysis in the clinical routine for the diagnosis of cutaneous squamous cell carcinoma.
\end{abstract}


Keywords: squamous cell carcinoma; optical diagnosis; laser spectroscopy; ATR-FTIR spectroscopy; hierarchical cluster analysis

\section{Introduction}

According to the World Health Organization (WHO), by 203,027 million new incident cases of cancer could be expected, 17 million cancer deaths annually and 75 million persons alive with cancer within five years of diagnosis [1]. The most common form of malignancy in humans is nonmelanoma skin cancer (NMSC) and represents nearly $95 \%$ of all cutaneous neoplasms [2]. In Brazil, according to the 2014 report of the National Cancer Institute, $30 \%$ of cases predicted are represented by NMSCs [3].

Most NMSCs are related to ultraviolet (UV) [2,4,5] light exposure and due to the heterogeneity of the skin, they may have different tumor lines. The most common types are basal cell carcinoma (BCC) and squamous cell carcinoma (SCC). Approximately $75 \%$ of diagnostics cases of NMSCs are related to $\mathrm{BCC}$ and $20 \%$ for SCC. Although more common, BCC is less aggressive and rarely presents metastasis. On the other hand, SCC is aggressive and shows a pattern of destructive growth with a metastatic profile.

Considering that early diagnosis has fundamental importance for a treatment with favorable results, the search for techniques that can provide supplementary information for physicians in detection of neoplasms in early stages have been subject of several scientific works [6-8]. In this sense, Fourier transform infrared spectroscopy (FTIR) can provide biochemical information complimentary to the morphological histopathology, using the same biopsy material. Biological molecular bonds with an electric dipole moment that can change by atomic displacement due to natural vibrations are infrared active and therefore are quantitatively measured by infrared spectroscopy [7].

FTIR spectra can be acquired mainly in three different experimental configurations: transmission, reflection-absorption (transflection) or attenuated total reflection (ATR) [9]. The first one operates by transmitting IR radiation through sample-substrate, whereas in transflection the radiation interacts with sample and is back reflected off by the substrate [9]. Finally, on the ATR mode the sample is placed on a crystal with refractive index higher than sample, inducing total internal reflection of incident radiation, which is attenuated and penetrates into the sample as an evanescent wave $[9,10]$.

Previous studies have discussed spectra alterations associated with transmission and transflection sampling mode. In transflection, the low-emissivity slides commonly used as reflector substrates contribute to formation of a standing wave perpendicular to sample surface that leads to spectral changes not related to the biochemistry of sample [11-13]. In transmission mode, spectra collected are subject to a variety of physical effects occurring in the same time with absorption, and requires corrections for phenomena, such as light scattering [14], refraction and dispersion [15], and other optical effects specifically relative to measuring thin films, which may also induce spectral distortions [16]. However, these unwanted spectral contributions are not presented in the ATR sampling mode [9], which provides to be a simple and powerful tool for analyze liquids and thin films samples with no preparation method [10]. ATR-FTIR spectroscopy provides a single spectrum, which represents the average signal from the sample area that light passed through [10]. Added to this, ATR sampling mode 
presents high SNR (signal-to-noise ratio) compared to those obtained by transflection and transmission configurations [7]. Measurements in ATR-FTIR spectroscopy may be performed as macro ATR-FTIR or fiber-ATR, which can be used in the future, directly on a patient's skin [17-19].

\section{Results}

\subsection{Histopathological Analysis}

The anatomopathological characteristics presented in a biological tissue is the gold standard for diagnosis of NMSCs. Figure 1 shows the profile of normal and neoplastic skin lesions induced by multi-stage chemical carcinogenesis in mice obtained by histopathological analysis.
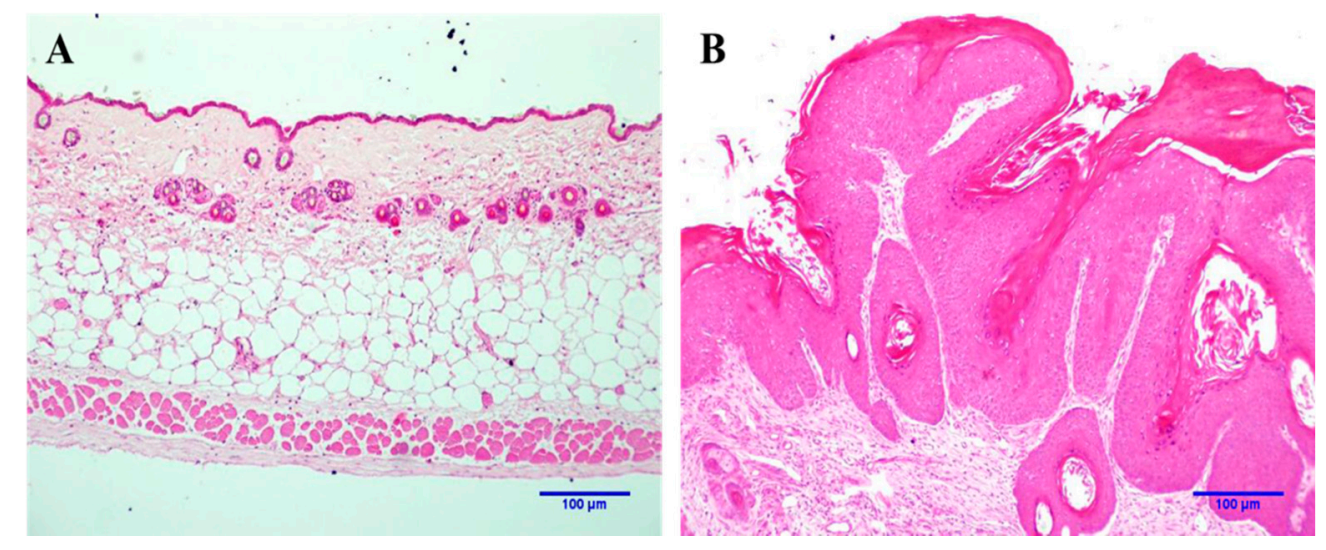

Figure 1. Light microscopy of representative histological sections hematoxylin-eosin (H\&E) stained; (A) Healthy skin and (B) Neoplastic lesion.

The anatomopathological characteristics for both tissues are clearly different. The epidermis of normal skin is consisted of three or four cell layers covered by a thin stratum corneum (Figure 1A), whereas neoplastic lesions show an intense proliferation of keratinocytes in an exophytic profile, covered by a thick stratum corneum (Figure 1B). Added to this, moderate dysplasia characterized by an intense nuclear hyperchromatism and cell pleomorphism was present in the epithelial basal layer of neoplastic lesions. The exophytic pattern of the epithelium associated with epithelial dysplasia was compatible with DMBA (7,12-dimethyl-benzanthracene)/TPA (12-O-tetradecanoyl-phorbol-13-acetate)induced neoplastic lesion in the skin.

\subsection{ATR-FTIR Spectroscopy}

ATR-FTIR spectroscopy was used to compare neoplastic lesions with normal skin tissues. Figure 2 shows the spectra from $900-1800 \mathrm{~cm}^{-1}$ (fingerprint region), which provides information of vibrational modes associated with important cell content. 


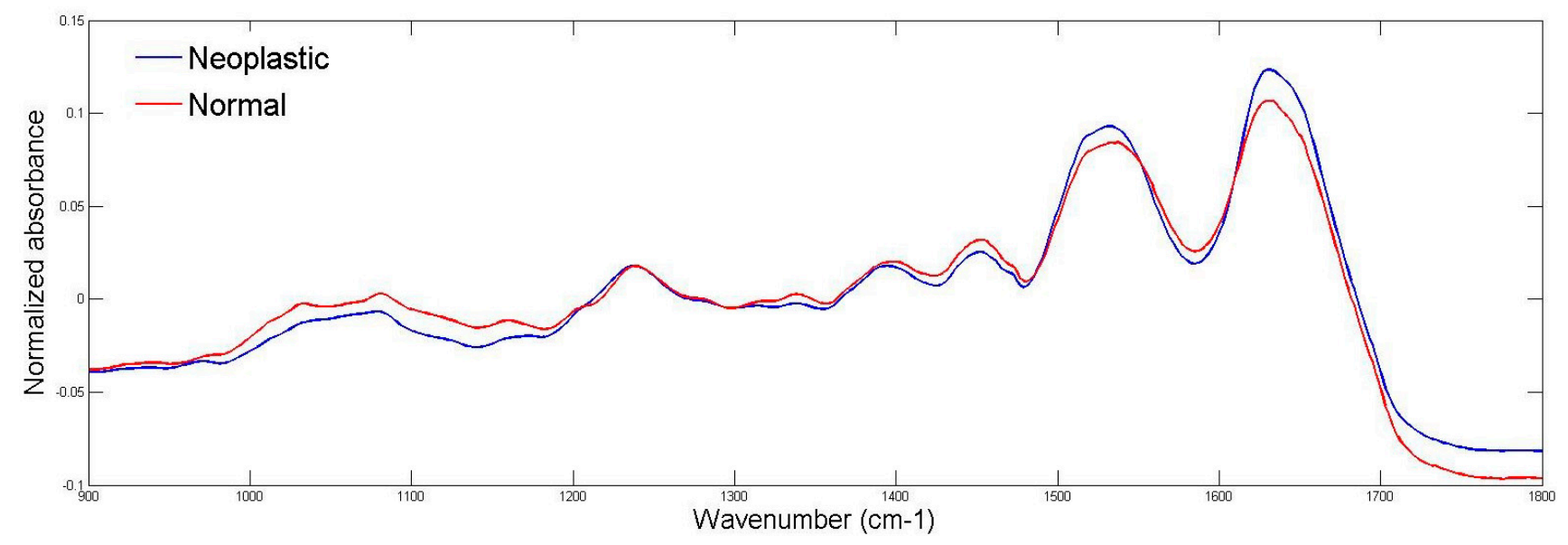

Figure 2. Fingerprint region (900-1800 $\mathrm{cm}^{-1}$ ) of normal (red line) and neoplastic lesions (blue line).

Due to the overlapping of sub-bands in the row spectra, we calculated the second derivative of absorbance to compare the averaged spectra, as shown in Figure 3.

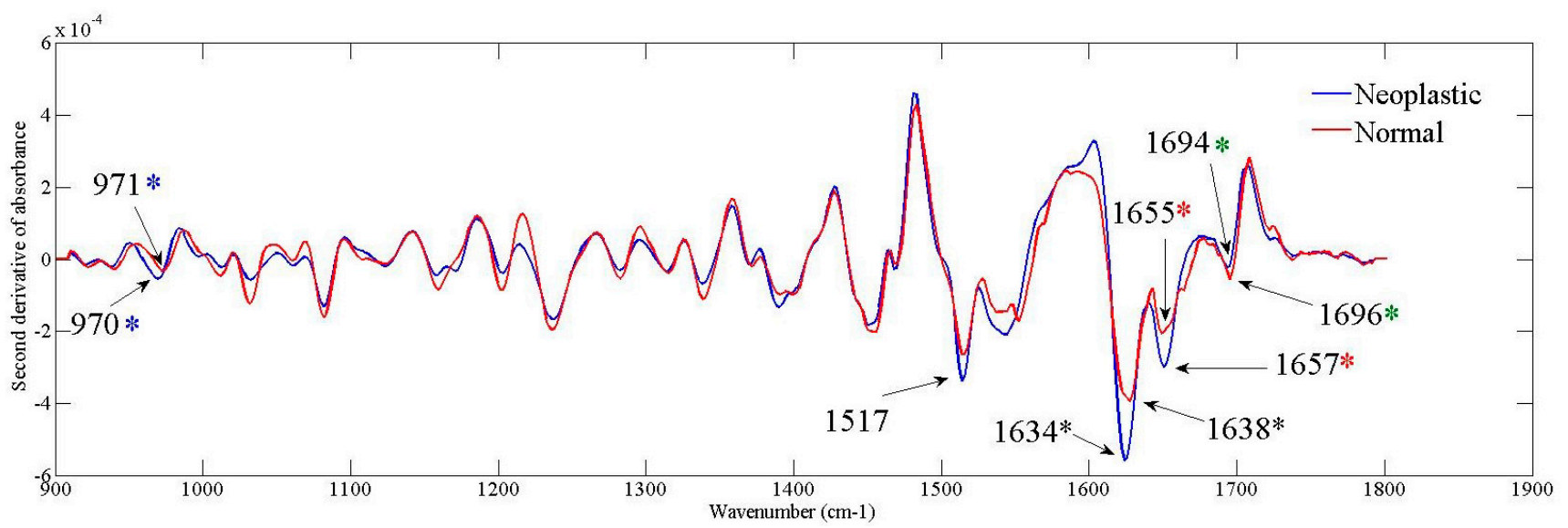

Figure 3. Second derivative of averaged spectra obtained for the neoplastic and normal tissues. The asterisks depict the shifts presented for the bands: Blue asterisk for $970 \mathrm{~cm}^{-1}$; Black asterisk to $1634 \mathrm{~cm}^{-1}$; Red asterisk for $1657 \mathrm{~cm}^{-1}$; Green asterisk to $1694 \mathrm{~cm}^{-1}$.

Both groups showed similar vibrational modes, in which some differences in the absorption intensities were observed, as well as shifts in the peak position.

Table 1 shows the band position of vibrational modes statistically different identified in the fingerprint region. The mean band intensity and its respective standard deviation are presented in the third and fourth columns, respectively, and the last column shows the $p$ value, thus indicating the differences between bands.

Band peaking at $971 \mathrm{~cm}^{-1}$ is related to symmetrical stretching mode of dianionic phosphate monoesters of phosphorylated proteins and nucleic acids [20-22]. Increased in its intensity was observed in neoplastic tissue compared to normal skin, as well as a slight shift for $970 \mathrm{~cm}^{-1}$ as depicted by blue asterisk in Figure 3. 
Table 1. Observed wavenumber values and their statistical comparison between assignments normal and neoplastic tissue, and the $p$ values ( $t$-student test).

\begin{tabular}{ccccc}
\hline \multicolumn{2}{c}{$\begin{array}{c}\text { ATR-FTIR Band } \\
\text { Positions }\left(\mathbf{c m}^{-\mathbf{1}}\right)\end{array}$} & Normal & $\boldsymbol{p}$ Value \\
\hline Normal & Neoplastic & Nand Intensity & Neoplastic \\
\hline 971 & 970 & $-3.919 \times 10^{-5} \pm 3.853 \times 10^{-6}$ & $-5.8 \times 10^{-5} \pm 3.536 \times 10^{-6}$ & 0.0007 \\
1517 & 1517 & $-2.68 \times 10^{-4} \pm 5.0 \times 10^{-6}$ & $-3.49 \times 10^{-4} \pm 8.726 \times 10^{-6}$ & 0.0001 \\
1638 & 1634 & $-4.1 \times 10^{-4} \pm 9.918 \times 10^{-6}$ & $-5.64 \times 10^{-4} \pm 1.393 \times 10^{-5}$ & 0.0001 \\
1655 & 1657 & $-2.14 \times 10^{-4} \pm 5.333 \times 10^{-6}$ & $-3.07 \times 10^{-4} \pm 1.430 \times 10^{-5}$ & 0.0001 \\
1694 & 1696 & $-5.641 \times 10^{-5} \pm 2.538 \times 10^{-6}$ & $-2.407 \times 10^{-5} \pm 2.270 \times 10^{-6}$ & 0.0001 \\
\hline
\end{tabular}

Spectral range from $1500-1700 \mathrm{~cm}^{-1}$ provide information peptide bonding in proteins and its secondary structure. Band peaking at $1517 \mathrm{~cm}^{-1}$ arise in the neoplastic tissue and it is reported to amide II vibration [20], which results from the combination out-of-phase of the $\mathrm{N}-\mathrm{H}$ in plane bend and the $\mathrm{C}-\mathrm{N}$ stretching vibration with smaller contributions from the $\mathrm{C}-\mathrm{O}$ in plane bend and the $\mathrm{C}-\mathrm{C}$ and $\mathrm{N}-\mathrm{C}$ stretching vibrations [23]. Bands located in $1638 \mathrm{~cm}^{-1}$ [24], $1655 \mathrm{~cm}^{-1}$ [20,23] and $1694 \mathrm{~cm}^{-1}[20,23]$ represent the amide I vibrations, characterized mainly from the $\mathrm{C}=\mathrm{O}$ stretching with minor contributions from the out-of-phase $\mathrm{C}-\mathrm{N}$ stretching, the $\mathrm{C}-\mathrm{C}-\mathrm{N}$ deformation and the $\mathrm{N}-\mathrm{H}$ in-plane bend [20,23]. Bands at 1638 and $1694 \mathrm{~cm}^{-1}$ are associated with the $\beta$-sheet secondary structure of proteins, more specifically to parallel and anti-parallel configuration. As shown in Figure 3, the vibrational mode associated to parallel $\beta$-sheet increased its intensity and shifted to a lower wavenumber (black asterisk) in the neoplastic tissue. On the other hand, the anti-parallel $\beta$-sheet shifted to a higher wavenumber (green asterisk) and decreased its intensity in the tumor spectra. Finally, the band in $1655 \mathrm{~cm}^{-1}$ is associated to the vibrations of the $\alpha$-helix structure of proteins and displays an increase in neoplastic tissue and it is shifted for a high wavenumber peak (red asterisk).

\subsection{Cluster Analysis}

Spectra of neoplastic and normal skin were pre-processed prior to the application of hierarchical cluster analysis (HCA) that was used as an unsupervised classification technique aiming at sorting the spectra into two categories. HCA was performed to evaluate the potential of the technique to differentiate the spectra of neoplastic and normal tissue. For this, second derivative of ATR-FTIR spectra were used to minimize linear baseline effects and correct quadratic effects caused by particle scatter. Results of clustering are displayed in a tree-like diagram called dendrogram, so that spectra within a same cluster should describe spectra with similar characteristics. Results of FTIR spectra classification are shown in Figure 4.

The dendrogram shown in Figure 4 classify all data into two groups. Samples named T1-T70 correspond to the spectra obtained for the tissue extracted from animals submitted to carcinogenesis (neoplastic group), whereas those named as N1-N70 represent the spectra obtained for the normal group. The way that the data are distributed in the groups is shown on the abscissa axis and the distance of spectra within the same cluster is shown on the ordinate axis. 


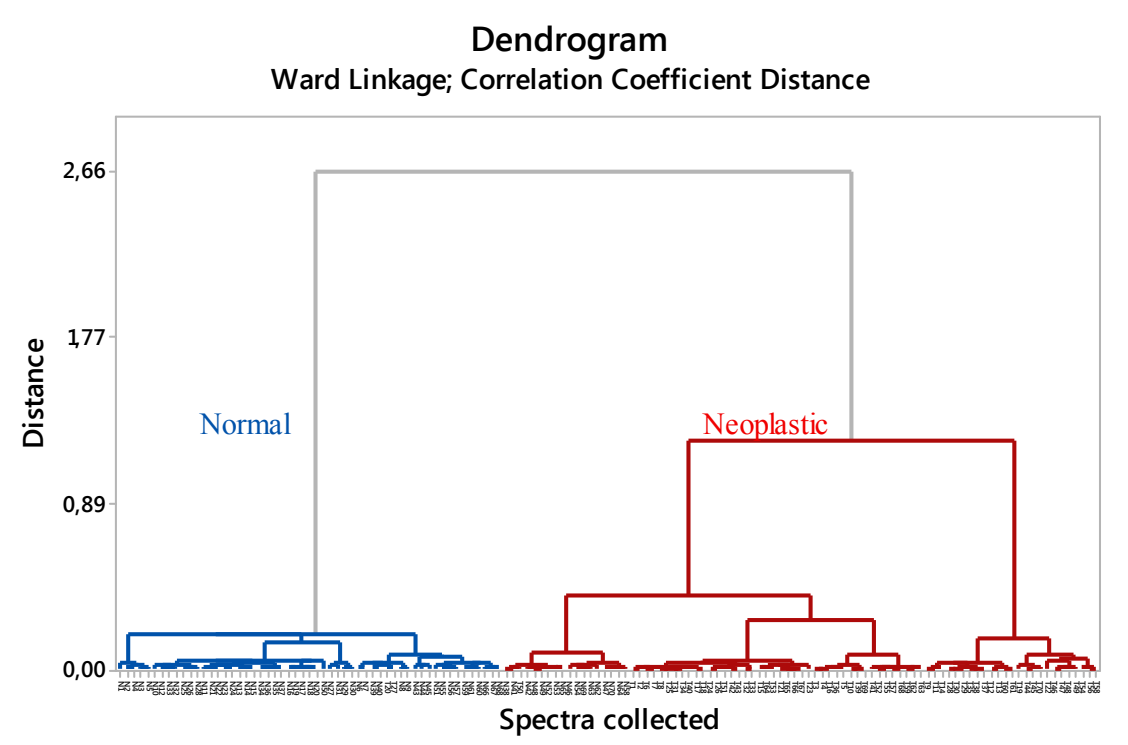

Figure 4. Classification of the dataset into two categories (normal in blue and neoplastic in red).

Considering the distribution of the data into the clusters obtained with HCA, the accuracy, sensitivity and specificity of classification was calculated as shown in Table 2.

Table 2. Distribution of the dataset in groups for the calculus of the accuracy of clustering classification.

\begin{tabular}{ccccccccc}
\hline & $\begin{array}{c}\text { True Positive } \\
\text { (TP) }\end{array}$ & $\begin{array}{c}\text { True Negative } \\
\text { (TN) }\end{array}$ & $\begin{array}{c}\text { False Positive } \\
\text { (FP) }\end{array}$ & $\begin{array}{c}\text { False Negative } \\
\text { (FN) }\end{array}$ & $\begin{array}{c}\text { Accuracy } \\
(\mathbf{\%})\end{array}$ & $\begin{array}{c}\text { Sensitivity } \\
(\boldsymbol{\%})\end{array}$ & $\begin{array}{c}\text { Specificity } \\
(\boldsymbol{\%})\end{array}$ \\
\hline Spectral data & 68 & 53 & 17 & 2 & 86.4 & 97.1 & 75.7 \\
\hline
\end{tabular}

For the calculus, we considered the true positive as the neoplastic spectra in the neoplastic group; true negative as the normal spectra in the normal group; the false positive as normal spectra in the neoplastic group; and false negative as neoplastic spectra in the normal group. The accuracy obtained for the classification of all dataset was $86.4 \%$, sensitivity was $97.1 \%$, and specificity $75.7 \%$.

\section{Discussion}

As previously described, the fingerprint spectral region provides important information related to the biochemistry of analyzed tissue. However, it is noticeable that the tissue-sample analysis is much more complex than the simple explanation of the features of single component vibration. In a biological system the effect of each structure may interact with the others and result in the amplification or reduction of a specific signature.

Band absorption at $970 \mathrm{~cm}^{-1}$ is assigned to vibrational modes of phosphorylated proteins, and it is increased for neoplastic tissue. Phosphorylation or dephosphorylation process can affect the function of a protein in every conceivable way, increasing or suppressing activity, marking a protein for destruction, allowing it to move from one subcellular compartment to another, or enabling it to interact with or dissociate from other proteins [25-27]. In this sense, phosphorylation processes are an important signaling pathway involved in processes related to cancer development. These protein changes can be assessed by FTIR spectra using information provided by vibrations associated to amide region, which is highly active and sensitive in infrared. 
Our findings indicated an increase in amide II band at $1517 \mathrm{~cm}^{-1}$ and suggest high level of protein expression, which may be explained by the intense metabolic activity of neoplastic tissue and its high demand for proteins performing signaling pathways for proliferation of cancer cell, oncogenic kinases signaling, transcriptional regulation, and other functions.

Sub-bands of amide I related to $\alpha$-helix $\left(1655 \mathrm{~cm}^{-1}\right)$ and parallel $\beta$-sheet $\left(1638 \mathrm{~cm}^{-1}\right)$ structures of proteins showed a higher increase and shifted in neoplastic tissue compared to normal skin. Parallel $\beta$-sheet shifted its position $4 \mathrm{~cm}^{-1}$ to a lower wavenumber direction (black asterisk in Figure 3), whereas a shift of $2 \mathrm{~cm}^{-1}$ in the direction of a higher wavenumbers was found for $\alpha$-helix structure (red asterisk in Figure 3). These results suggest changes in hydrogen bonding between peptide groups and consequently in molecular geometry of proteins, which may induce damages in protein folding and result in definitive loss of protein biological function or mutation.

\section{Experimental Section}

\subsection{Chemical Carcinogenesis}

For induction of the neoplasia, we used a well-established in vivo model of chemically-induced skin tumor on mice. We used 16 Swiss female mice, aged from 8 to 10 weeks, with a weight of $20 \mathrm{~g}$. The animals were anesthetized with ketamine $(0.35 \mathrm{~mL} / \mathrm{kg})$ and xylazine $(0.20 \mathrm{~mL} / \mathrm{kg})$ during all stages of the protocol, which was approved by the ethics committee for research on animals (Comite de Etica no Uso de Animais, CEUA) of Instituto de Pesquisas Energéticas e Nucleares (IPEN) (project no. 71/10-CEUA-IPEN/SP, 21 December 2010). The mice were divided into 2 groups (Table 3).

Table 3. Mice groups.

\begin{tabular}{ccc}
\hline Group & Treatment & Description \\
\hline Group $1(n=13)$ & Normal & Normal skin \\
Group 2 $(n=13)$ & Neoplasia & Neoplastic skin \\
\hline
\end{tabular}

The chemical carcinogenesis consisted of two stages. The initiation phase was a topical application on the shaved backs of $50 \mathrm{mg}$ DMBA (7,12-dimethyl-benzanthracene) diluted in $100 \mathrm{~mL}$ of acetone. The promotion phase began one week after and consists in a bi-weekly application of $5 \mathrm{~g}$ of TPA (12-O-tetradecanoyl-phorbol-13-acetate) diluted in $200 \mathrm{~mL}$ of acetone, during 28 weeks. After 28 weeks, the animals obtained visible single or multiple tumor nodules with verrucous aspect (Figure 5). The control group only received topical application of acetone [28].

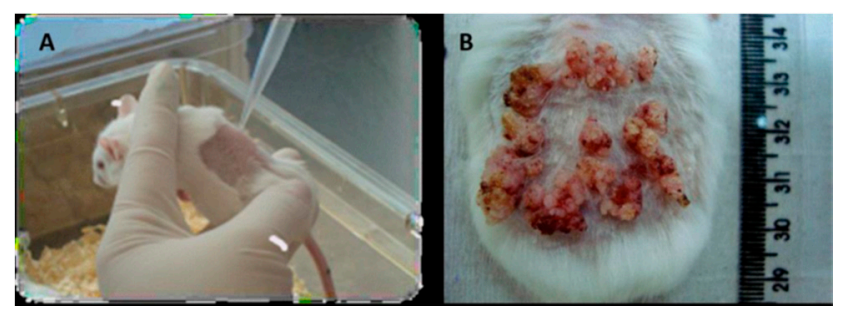

Figure 5. Macroscopic view of the skin lesions. (A) Topical application of carcinogenic substance in mouse skin; (B) Neoplastic lesions obtained with chemical carcinogenesis after 28 weeks. 
Tissue was extracted by biopsy and kept in formaldehyde for $24 \mathrm{~h}$ to the histological fixation. Once fixed, the biological tissues were diaphanized in two baths of pure xylol for $30 \mathrm{~min}$ and dehydrated with ethanol baths in increasing concentrations (50\%, 70\% and 100\%). After the dehydration, the samples were mounted in wax blocks and slices of $5 \mu \mathrm{m}$ thickness were obtained from FFPP (Formalin-fixed paraffin-processed) sections using a microtome and placed in MirrIR low-E-coated slides (Kevley Technologies, Chesterland, OH, USA) for the spectroscopic analysis.

Due to the spectral contributions of paraffin in the used wavenumber range, FFPP sections were submitted to dewaxing protocol [29]. For this purpose, FFPP sections were immersed in a series of baths consisting of two baths of xylene during $10 \mathrm{~min}$ and one bath of absolute ethanol during $5 \mathrm{~min}$. After this, samples were kept in a desiccator for $24 \mathrm{~h}$.

\subsection{ATR-FTIR Spectroscopy}

ATR-FTIR measurements, in the range $4000-400 \mathrm{~cm}^{-1}$, with $4 \mathrm{~cm}^{-1}$ of spectral resolution, were recorded using an Attenuated Total Reflectance (Smart Orbit, Thermo Scientific, Waltham, MA, USA) accessory coupled to a Fourier transform infrared spectrometer (Thermo Nicolet 6700, Waltham, MA, USA) system. The samples were pressed into the diamond crystal of ATR with a standardized pressure using a manometer. FTIR spectrometer was fitted with a deuterated triglycine sulfate (DTGS) detector (Thermo Scientific). For each spectrum, 100 scans were co-added and the spectrum obtained for each sample represents the averaged from 10 replicates measured in each sample. The Thermo Scientific system was controlled with Omnic software (Thermo Scientific).

Second derivative of spectra were smoothed with a Savitzky-Golay filter with a polynomial of second order in an eleven points window. Hierarchical cluster analysis (HCA) was used as an unsupervised classification technique in order to evaluate the similarity level between spectral data structures. The similarity of different clusters was defined by correlation coefficient distance and calculated by Ward's method in the second derivative spectrum for each sample using software Minitab 17 (Minitab Inc., State College, PA, USA).

\section{Conclusions}

The current study shows that clustering analysis showed $86.4 \%$ accuracy in classifying spectra of neoplastic lesions from normal tissue, which presented mainly differences in the wavenumbers associated with the protein content. In this sense, ATR-FTIR spectroscopy provides a useful tool to complement histopathological analysis in the clinical routine for the diagnosis of SCC.

\section{Acknowledgments}

This work was supported by Fundação de Amparo à pesquisa do Estado de São Paulo (FAPESP)/ Centros de Pesquisa Inovação e Difusão (CEPID) 05/51689-2, Coordenação de Aperfeiçoamento de Pessoal de Nível Superior (CAPES)/Programa Nacional de Cooperação Acadêmica PROCAD 071/201388881.068505/2014-01); Conselho Nacional de Desenvolvimento Científico e Tecnológico (CNPq), Instituto Nacional de Ciência e Tecnologia Fotonica (INCT) 573.916/2008-0 and Produtividade em Pesquisa (PQ) 312397/2013-5. 


\section{Author Contributions}

Denise M. Zezell conceived and designed the experiments; Viviane P. Goulart performed the induction of the chemical carcinogenesis on the animals and the confection of the slides; Cassio A. Lima performed the spectroscopic experiments and the data analysis; Luciana Correa contributed with the histopathological analysis; Thiago M. Pereira complemented the HCA analysis. Denise M. Zezell and Cassio A. Lima wrote the paper.

\section{Conflicts of interest}

The authors declare no conflict of interest.

\section{References}

1. World Health Organization, WHO. Available online: http://www.iarc.fr/en/publications/ pdfs-online/wcr/2008/wcr_2008.pdf (accessed on 12 December 2014).

2. Dubas, L.; Ingraffea, A. Nonmelanoma skin cancer. Facial Plast. Surg. Clin. N. Am. 2013, 21, 43-53.

3. Instituto Nacional de câncer, INCA. Available online: http://www.inca.gov.br/estimativa/2014/ (accessed on 12 December 2014).

4. Lee, D.; Miller, S. Nonmelanoma skin cancer. Facial Plast. Surg. Clin. N. Am. 2009, 17, 309-324.

5. Kim, R.H.; Armstrong, A.W. Nonmelanoma skin cancer. Dermatol. Clin. 2012, 30, 125-139.

6. Diem, M.; Milijkovic, M; Bird, B.; Chernenko, T.; Schubert, J.; Marcsisin, E.; Mazur, A.; Kingston, E.; Zuser, E.; Papamarkakis, K.; et al. Applications of Infrared and Raman microspectroscopy of cells and tissue in medical diagnosis: Present status and future promises. Spectroscopy 2012, 27, 463-496.

7. Baker, M.J.; Trevisan, J.; Bassan, P.; Bhargava, R.; Butler, H.J.; Dorling, K.M.; Fielden, P.R.; Fogarty, S.W.; Fullwood, N.J.; Heys, K.A.; et al. Using Fourier transform IR spectroscopy to analyze biological materials. Nat. Protoc. 2014, 9, 1771-1791.

8. Petrich, W. MID-Infrared and Raman spectroscopy for medical diagnostics. Appl. Spectrosc. Rev. 2011, 36, 181-237.

9. Dorling, M.K.; Baker, M.J. Highlighting attenuated total reflection Fourier transform infrared spectroscopy for rapid serum analysis. Trends Biotechnol. 2013, 31, 327-328.

10. Kazarian, S.; Chan, K.L. ATR-FTIR spectroscopic imaging: Recent advances and applications to biological systems. Analyst 2013, 138, 1940-1951.

11. Greenler, R. Infrared study of adsorbed molecules on metal surfaces by reflection techniques. J. Chem. Phys. 1966, 44, 310-315.

12. Filik, J.; Frogley, M.D.; Pijanka, J.K.; Wehbe, K.; Cinque, G. Electric field standing wave artefacts in FTIR micro-spectroscopy of biological materials. Analyst 2012, 137, 853-861.

13. Bassan, P.; Sachdeva, A.; Lee, J.; Gardner, P. Substrate contributions in micro ATR of thin samples: Implications for analysis of cells, tissue and biological fluids. Analyst 2013, 38, 4139-4146. 
14. Bassan, P.; Kohler, A.; Martens, H.; Lee, J.; Byrne, H.J.; Dumas, P.; Gazi, E.; Brown, M.; Clarke, N.; Gardner, P. Resonant Mie scattering (RMieS) correction of infrared spectra from highly scattering biological samples. Analyst 2010, 135, 268-277.

15. Chan, K.L.A.; Kazarian, S.G. Correcting the effect of refraction and dispersion of light in FT-IR spectroscopic imaging in transmission through thick infrared windows. Anal. Chem. 2013, 85, 1029-1036.

16. King, S.W.; Milosevic, M. A method to extract absorption coefficient of thin films from transmission spectra of the films on thick substrates. J. Appl. Phys. 2012, 111, 073109.

17. Sukuta, S.; Bruch, R. Factor analysis of cancer Fourier transform infrared evanescent wave fiberoptical (FTIR-FEW) spectra. Lasers Surg. Med. 1999, 24, 382-388.

18. Afanasyeva, N.I.; Kolyakov, S.F.; Letokhov, V.S.; Sokolov, V.V.; Frank, G.A. Diagnostics of cancer by fiber optic evanescent wave FTIR (FEW-FTIR) spectroscopy. Proc. SPIE 1996, $2928,154$.

19. Spielvogel, J.; Lobik, L.; Nissencorn, I.; Hibst, R.; Gotshal, Y.; Katzir, A. Cancer diagnostics using Fourier transform fiber optic infrared evanescent wave spectroscopy (FTIR-FEWS). Proc. SPIE 1998, 3262, 185.

20. Movasaghi, Z.; Rehman, S.; ur Rehman, D.I. Fourier transform infrared (FTIR) spectroscopy of biological tissues. Appl. Spectrosc. Rev. 2008, 43, 134-179.

21. Wood, B.R.; Quinn, M.A.; Burden, F.R.; McNaughton, D. An investigation into FT-IR spectroscopy as a bio-diagnostic tool for cervical cancer. Biospectroscopy 1996, 2, 143-153.

22. Argov, S.; Sahu, R.K.; Bernshtain, E.; Salam, A.; Shohat, G.; Zelig, U.; Mordechai, S. Inflammatory bowel diseases as an intermediate stage between normal and cancer: A FTIR-microspectroscopy approach. Biopolymers 2004, 75, 384-392.

23. Barth, A. Infrared spectroscopy of proteins. Biochim. Biophys. Acta 2007, 1767, 1073-1101.

24. Khurana, R.; Fink, A. Do parallel-helix proteins have a unique Fourier transform infrared spectrum? Biophys. J. 2000, 78, 994-1000.

25. Cohen, P. The role of protein phosphorylation in human health and disease. Eur. J. Biochem. 2001, 268, 5001-5010.

26. Reimand, J.; Wagih, O.; Bader, G.D. The mutational landscape of phosphorylation signaling in cancer. Sci. Rep. 2013, 3, 2651.

27. Zanivan, S.; Cox, J.; Meves, A.; Fässler, R.; Neilson, L.J.; Tang, H.R.; Kalna, G.; Machesky, L.M.; van Ree, J.H.; van Deursen, J.M.; et al. In vivo SILAC-based proteomics reveals phosphoproteome changes during mouse skin carcinogenesis. Cell Rep. 2013, 3, 552-566.

28. Abel, E.; Angel, J.; Kiguchi, K. Multi-stage chemical carcinogenesis in mouse skin: Fundamentals and applications. Nat. Protoc. 2009, 4, 1350-1362.

29. Mian, S.; Colley, H.; Thornhill, M.; Rehman, I. Development of a dewaxing protocol for tissue-engineered models of the oral mucosa used for Raman spectroscopic analysis. Appl. Spectrosc. Rev. 2014, 49, 614-617.

(C) 2015 by the authors; licensee MDPI, Basel, Switzerland. This article is an open access article distributed under the terms and conditions of the Creative Commons Attribution license (http://creativecommons.org/licenses/by/4.0/). 